\title{
Phased Array Noise Source Localization Measurements of an F404 Nozzle Plume at Both Full and Model Scale
}

Gary G. Podboy, James E. Bridges, and Brenda S. Henderson

Glenn Research Center, Cleveland, Ohio 


\section{NASA STI Program . . . in Profile}

Since its founding, NASA has been dedicated to the advancement of aeronautics and space science. The NASA Scientific and Technical Information (STI) program plays a key part in helping NASA maintain this important role.

The NASA STI Program operates under the auspices of the Agency Chief Information Officer. It collects, organizes, provides for archiving, and disseminates NASA's STI. The NASA STI program provides access to the NASA Aeronautics and Space Database and its public interface, the NASA Technical Reports Server, thus providing one of the largest collections of aeronautical and space science STI in the world. Results are published in both non-NASA channels and by NASA in the NASA STI Report Series, which includes the following report types:

- TECHNICAL PUBLICATION. Reports of completed research or a major significant phase of research that present the results of NASA programs and include extensive data or theoretical analysis. Includes compilations of significant scientific and technical data and information deemed to be of continuing reference value. NASA counterpart of peer-reviewed formal professional papers but has less stringent limitations on manuscript length and extent of graphic presentations.

- TECHNICAL MEMORANDUM. Scientific and technical findings that are preliminary or of specialized interest, e.g., quick release reports, working papers, and bibliographies that contain minimal annotation. Does not contain extensive analysis.

- CONTRACTOR REPORT. Scientific and technical findings by NASA-sponsored contractors and grantees.
- CONFERENCE PUBLICATION. Collected papers from scientific and technical conferences, symposia, seminars, or other meetings sponsored or cosponsored by NASA.

- SPECIAL PUBLICATION. Scientific, technical, or historical information from NASA programs, projects, and missions, often concerned with subjects having substantial public interest.

- TECHNICAL TRANSLATION. Englishlanguage translations of foreign scientific and technical material pertinent to NASA's mission.

Specialized services also include creating custom thesauri, building customized databases, organizing and publishing research results.

For more information about the NASA STI program, see the following:

- Access the NASA STI program home page at http://www.sti.nasa.gov

- E-mail your question via the Internet to help@ sti.nasa.gov

- Fax your question to the NASA STI Help Desk at $443-757-5803$

- Telephone the NASA STI Help Desk at 443-757-5802

- Write to: NASA Center for AeroSpace Information (CASI) 7115 Standard Drive Hanover, MD 21076-1320 


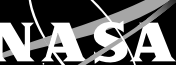

Phased Array Noise Source Localization Measurements of an F404 Nozzle Plume at Both Full and Model Scale

Gary G. Podboy, James E. Bridges, and Brenda S. Henderson

Glenn Research Center, Cleveland, Ohio

Prepared for the

Turbo Expo 2010

sponsored by the American Society of Mechanical Engineers

Glasgow, Scotland, United Kingdom, June 14-18, 2010

National Aeronautics and

Space Administration

Glenn Research Center

Cleveland, Ohio 44135 


\section{Acknowledgments}

The authors wish to thank Dr. John T. Spyropoulos of NAVAIR for inviting them to the Naval Air Engineering Station to acquire the full-scale engine source location data presented in this report. This work was supported by the NASA

Fundamental Aeronautics Program, Supersonics Project.

Trade names and trademarks are used in this report for identification only. Their usage does not constitute an official endorsement, either expressed or implied, by the National Aeronautics and Space Administration.

This work was sponsored by the Fundamental Aeronautics Program at the NASA Glenn Research Center.

Level of Review: This material has been technically reviewed by technical management.

Available from

NASA Center for Aerospace Information 7115 Standard Drive

Hanover, MD 21076-1320
National Technical Information Service 5301 Shawnee Road Alexandria, VA 22312

Available electronically at http://gltrs.grc.nasa.gov 


\title{
Phased Array Noise Source Localization Measurements of an F404 Nozzle Plume at Both Full and Model Scale
}

\author{
Gary G. Podboy, James E. Bridges, and Brenda S. Henderson \\ National Aeronautics and Space Administration \\ Glenn Research Center \\ Cleveland, Ohio 44135
}

\begin{abstract}
A 48-microphone planar phased array system was used to acquire jet noise source localization data on both a full-scale F404-GE-F400 engine and on a $1 / 4^{\text {th }}$ scale model of a F400 series nozzle. The full-scale engine test data show the location of the dominant noise sources in the jet plume as a function of frequency for the engine in both baseline (no chevron) and chevron configurations. Data are presented for the engine operating both with and without afterburners. Based on lessons learned during this test, a set of recommendations are provided regarding how the phased array measurement system could be modified in order to obtain more useful acoustic source localization data on high-performance military engines in the future. The data obtained on the $1 / 4^{\text {th }}$ scale F400 series nozzle provide useful insights regarding the full-scale engine jet noise source mechanisms, and document some of the differences associated with testing at model-scale versus fullscale.
\end{abstract}

\section{Introduction}

The very high levels of jet noise produced by highperformance military aircraft during take-off and landing operations pose serious health risks to personnel working on aircraft carriers. While the United States Navy considers prolonged exposure to sounds above $84 \mathrm{~dB}$ as having the potential to cause hearing loss, noise levels on a carrier flight deck can often exceed 145 dBA (Ref. 1). Depending on the susceptibility of the exposed individual, a single exposure to impulse noise with a peak level of $140 \mathrm{~dB}$ SPL may be hazardous (Ref. 2).

The unsafe noise levels are not confined to the carrier flight deck. Typically, 1400 sailors live and work on the gallery deck, where noise levels often exceed $100 \mathrm{dBA}$. These high noise levels impair the ability to communicate, reduce cognitive skill levels, and can result in permanent hearing loss.

Noise induced hearing loss is the leading occupational health expense for the US Navy. In 2004, the Veterans Administration paid $\$ 108$ million dollars in disability payments to 15,800 former Navy personnel for hearing loss an increase of $\$ 65$ million over 1999 levels (Ref. 3).

The severity of this problem has prompted a number of studies aimed at characterizing the jet noise produced by military aircraft engines. By analyzing F-15 flyover data, Norum, et al. (Ref. 4) investigated the effects of high speed flight on the exhaust noise produced from overexpanded jets. Gee, et al. (Ref. 5) examined F/A-18E acoustic data in order to determine the role that nonlinear noise propagation plays in spectral broadening. Schlinker et al. (Ref. 6) conducted an extensive study of data obtained during a ground test of an unspecified military engine. They obtained acoustic data in the near field, the far field and the very far field in an effort to characterize the propagation of high intensity, impulsive jet exhaust noise. They also measured the axial distribution of noise sources in the jet plume using a linear phased array.

Besides merely characterizing the noise, the US Navy has also begun to investigate noise reduction technologies aimed at lessening the adverse effects of jet noise. The objective is to develop technologies which reduce the noise at the source. Adding chevrons to the exhaust nozzles of commercial, subsonic aircraft has proven to be an effective noise reduction technology for medium- and high-bypass ratio turbofan engines (Refs. 10 and 11). Chevrons are triangular serrations in the nozzle trailing edge which induce streamwise vorticity into the shear layer. This added streamwise vorticity increases turbulent mixing which, in turn, tends to reduce jet noise. The application of chevrons to military aircraft is particularly attractive since existing engines can be retrofitted with these noise reduction devices. The exhaust jets of high performance tactical aircraft at takeoff, however, are typically overexpanded. Consequently, chevrons designed for subsonic jet noise reduction may not be effective in military engine applications.

In July 2009, a test was conducted at the Outdoor Test Stand at the Naval Air Engineering Station at Lakehurst, New Jersey, USA, in order to determine the extent to which chevrons can reduce the jet noise generated by a F404-GEF400 engine. The F404 is a low-bypass, high specific thrust engine which powers the F/A-18 aircraft. The primary objective of this test was to obtain both near-field and far-field acoustic data which could be used to determine the extent to which the chevrons reduce the noise produced by the engine relative to a baseline (no chevron) configuration, especially when the engine was operated with afterburners on. This test represents the first known use of chevrons on a military engine which employed the use of afterburners. The acoustic data obtained during this test indicate that the chevrons were effective at reducing the jet noise in the peak noise direction when the engine was operating with afterburners on. Details regarding these near-field and far-field acoustic results are presented by Martens, et al. (Ref. 7). 
A secondary test objective was to obtain phased array source localization data on the noise sources within the jet plume and to determine the effect that chevrons have on these noise sources. Such data could help guide the development of future noise reduction technologies for military engine applications. The test was also conducted to evaluate the suitability of a commercially-available OptiNav Inc. Array 48 phased array system for this large-sized, high-sound-level application and to determine what changes to the measurement system would be required in order to obtain more useful acoustic source localization data on military engines in the future. The purpose of this paper is to present phased array data acquired during this full-scale engine test that 1) provide information regarding the location of the noise sources within the jet plume for both chevron and no chevron configurations, and 2) demonstrate the suitability of the Array48 phased array system for this application. In addition to these full-scale data, an extensive set of noise source localization data obtained with the Array48 system on a $1 / 4^{\text {th }}$ scale model of an F400 series nozzle are also provided. These model scale data provide useful insights regarding the full-scale engine jet noise source mechanisms, and document some of the differences associated with testing at model-scale versus full-scale. The data obtained during these tests supports milestones of the NASA Fundamental Aeronautics Program, Supersonics Project to 1) demonstrate that phased arrays can locate noise sources in 3D shocked jets, 2) establish a supersonic aeroacoustic database for $3 \mathrm{D}$ dual-flow supersonic jets, and 3) deliver noise data from military engines to NASA partners.

\section{Nomenclature}

\begin{tabular}{|c|c|}
\hline $\mathrm{a}_{\text {local }}$ & local speed of sound \\
\hline$a_{\mathrm{amb}}$ & ambient speed of sound \\
\hline b & beamforming result \\
\hline BBSN & broadband shock noise \\
\hline$c$ & the speed of sound \\
\hline $\mathrm{C}$ & cross spectral matrix \\
\hline g & steering vector \\
\hline IRP & intermediate rated ( $\max$. nonafterburning) power \\
\hline $\mathrm{M}_{\mathrm{a}}$ & acoustic Mach number $=\mathrm{U}_{\text {jet }} / \mathrm{a}_{\mathrm{amb}}$ \\
\hline $\mathrm{M}_{\mathrm{jet}}$ & jet Mach number $=\mathrm{U}_{\text {jet }} / \mathrm{a}_{\text {local }}$ \\
\hline PLA & power lever angle, deg \\
\hline $\mathrm{P}_{\mathrm{amb}}$ & ambient pressure \\
\hline $\mathrm{P}_{\mathrm{t} \text { bypass }}$ & bypass total pressure \\
\hline $\mathrm{P}_{\mathrm{t} \text { core }}$ & core total pressure \\
\hline $\mathrm{T}_{\mathrm{amb}}$ & ambient temperature \\
\hline $\mathrm{T}_{\mathrm{t} \text { bypass }}$ & bypass total temperature \\
\hline $\mathrm{T}_{\mathrm{t} \text { core }}$ & core total temperature \\
\hline $\mathrm{T}_{\mathrm{s}}$ & jet static temperature \\
\hline $\mathrm{U}_{\text {jet }}$ & jet velocity \\
\hline$\vec{x}$ & grid point location \\
\hline$\vec{y}$ & microphone location \\
\hline$\omega$ & angular frequency \\
\hline $\mathbf{w}$ & normalized steering vector \\
\hline
\end{tabular}

\section{Research Instrumentation}

\section{Test Hardware}

The F404-GE-F400 is a two-spool, low-bypass axial flow turbofan which employs afterburners for thrust augmentation (Ref. 9). It contains a three-stage fan driven by a single-stage low pressure turbine and a seven-stage high-pressure compressor driven by a single-stage, high-pressure turbine. Approximately $1 / 4^{\text {th }}$ of the air passing through the fan stage is bypassed to the afterburner for combustion and cooling. The area of the exhaust nozzle is controlled using 12 sectored hinge seals and 12 forward primary flap hinges. The nozzleexit to nozzle-throat area ratio is a function of the power setting, and is not set to provide ideal expansion at most operating conditions. More information on the F404 engine is provided by Walton, et al. (Ref. 9).

The F404 engine is controlled by adjusting a single throttle control, the power level angle (PLA). A PLA setting of $35^{\circ}$ corresponds to engine idle, while $102^{\circ}$ represents the maximum nonafterburning power setting, referred to as the intermediate rated power (IRP). The maximum afterburning power setting occurs at PLA $=130^{\circ}$. This report will present source localization results for PLA settings of $83^{\circ}, 102^{\circ}$, and $130^{\circ}$. Changing the power lever angle results in changes to the exhaust-nozzle area, turbine speeds, internal temperatures, and fuel flow rate.

The F404 engine test was conducted at the Outdoor Test Stand at the Naval Air Engineering Station at Lakehurst, New Jersey, USA. The engine was mounted approximately $2.9 \mathrm{~m}$ above the surrounding concrete ground plane. A photo of the engine on the test stand is shown in Figure 1.

The test involving the $1 / 4^{\text {th }}$ scale model of the F400 series nozzle took place at the Nozzle Acoustic Test Rig (NATR) at the NASA John H. Glenn Research Center (GRC) in Cleveland, Ohio, USA. The NATR is a $1.35 \mathrm{~m}$ diameter freejet used to simulate forward flight conditions during the nozzle tests. It is located within the Aeroacoustic Propulsion Laboratory (AAPL), a $19.8 \mathrm{~m}$ radius anechoic geodesic dome. The interior surface of the dome is covered with sound absorbing acoustic wedges. Nozzles tested at NATR are mounted on the aft end of the High Flow Jet Exit Rig (HFJER) that is located at the exit of the NATR duct. Heated air is delivered from the facility compressed air system to the test nozzle via the HFJER. A dual flow capability allows both the primary and bypass streams of the full-scale engine to be simulated at model-scale. More information on the NATR is available in Soeder, et al. (Ref. 12).

The $1 / 4^{\text {th }}$ scale baseline nozzle used during the test is shown mounted to the High Flow Jet Exit Rig in Figure 2. Although this is a fixed-area nozzle, it is similar to the full-scale nozzle in that: 1) the convergent-divergent section is made up of two conic sections, and 2) the internal surface is faceted to simulate the flaps and seals which provide the area change capability in the full-scale nozzle. The nozzle exit and nozzle throat diameters are fixed at 12.87 and $11.43 \mathrm{~cm}$, respectively, 
and the design Mach number is 1.65. Flow conditions corresponding to test points for which data are presented later in this report are presented in Table 1. Values are provided in the table for the core and bypass flows and also for the mixed stream in the exhaust jet downstream of the nozzle exit. The mixed stream conditions provided in columns 2 through 4 were determined assuming that the core and bypass flows mix completely. The results presented later in this report will be identified by these mixed stream conditions. Note that none of the hot conditions listed in this table mimic any of the engine operating conditions set during the full-scale test. At the corresponding Mach numbers, the full-scale jet flow was always hotter than that produced at model-scale.

The chevrons used during the model-scale test (referred to in other publications as the P03L08W10 chevrons) were mounted at the nozzle exit as shown in Figure 3. Twelve chevrons were used, one on each facet. As shown in Figure 4 the chevron penetration was defined as the distance from the line extended along the inner conical surface to the chevron tip, the length was defined at the curved distance along the chevron surface from the nozzle trailing edge to the chevron tip, and the width was given by the width of the chevron base relative to the nozzle facet width. The chevrons used during the model-scale test had a penetration of $7.62 \mathrm{~mm}$, a length of $19.1 \mathrm{~mm}$, and a width of 100 percent.

\section{The Phased Array System}

Figure 5 shows both front and rear views of the OptiNav Array48 phased array system used during this test. This system consists of 48 Earthworks M30 microphones flush-mounted to a 1 by $1 \mathrm{~m}$ aluminum plate. The microphones are arranged in a series of log spirals in an effort to reduce sidelobes (errors in the phased array data). The microphones have $1 / 4^{\text {th }}$ in. diameter diaphragms and a flat frequency response over a frequency range of $5 \mathrm{~Hz}$ to $30 \mathrm{kHz}$. They can be used to measure sound pressure levels as high as $142 \mathrm{~dB}$ before they begin to saturate (136 dB when flush mounted in the array plate).

The photo at the right in Figure 5 shows the microphones mounted to the back of the array plate and a camera located at the center of the plate. There is a hole in the center of the plate through which the camera can be used to take a photo of the "field of view" of the phased array system. The phased array data reduction software superimposes the acoustic source localization data on top of the image taken with the phased array camera.

The phased array data were reduced using classical beamforming in the frequency domain. Classical beamforming assumes that the noise sources are incoherent, stationary point sources. The first step in the data reduction process was to compute the cross spectral matrix, $\mathrm{C}$, from the array data using the periodogram method with Hann windowing functions and 50 percent block overlap. The diagonal elements of the cross spectral matrix are then deleted (yielding $\overline{\mathrm{C}}$ ), and the beamforming result, $b$, at a given grid point, $k$, is computed using the classical beamforming expression

$$
b_{k}=\mathbf{w}_{\mathrm{k}}^{\prime} \overline{\mathbf{C}} \mathbf{w}_{\mathrm{k}}
$$

where $\mathbf{w}_{\mathrm{k}}$ is a normalized version of the steering vector $\boldsymbol{g}_{k}$. The individual elements of $\boldsymbol{g}_{k}$ represent the Green's function for a monopole located at grid point $\mathrm{k}$ as observed by microphone $i$. In free space with no flow

$$
g_{k i}=\frac{e^{j \frac{\omega}{c}\left|\vec{y}_{i}-\vec{x}_{k}\right|}}{\left|\vec{y}_{i}-\vec{x}_{k}\right|}
$$

where $\vec{x}_{k}$ and $\vec{y}_{i}$ denote the locations of grid point $k$ and microphone $i$, respectively. A beamforming result is computed for each point in a beamforming grid. The results corresponding to an entire grid are then displayed as color contour maps (referred to as beamform maps).

The output of the phased array data reduction routine is a stack of beamform maps. Each beamform map in the stack corresponds to a different frequency band. The maps are arranged in the stack such that the lowest frequency band is at the top of the stack, and the highest frequency band is at the bottom. Each beamform map shows the location of the dominant noise source or sources in the corresponding frequency band as a 2D color contour map overlaid on top of a photograph taken with the phased array camera. The color contours correspond to the location and strength of the noise sources found within an image plane (the beamform grid) at some specified location away from the microphone array. The user selects the location of the image plane by specifying a microphone-array-to-image-plane distance. Usually this image plane is parallel to the microphone array and usually its location is selected to coincide with a region where dominant noise sources are suspected, such as along the centerline of a jet flow. The dynamic range of the color contours (max value minus min value) is the same for each beamform map in the stack, but the peak value varies from map to map. The number of maps in the stack and the bandwidth corresponding to each map depends on how the data are processed. The data can be processed into $1 / 12^{\text {th }}$ octave, $1 / 3^{\text {th }}$ octave, octave, narrowband, or kilohertz bands or into one OASPL band.

\section{Phased Array Deployment}

During the full-scale test, data were acquired with the microphone array at four different locations relative to the engine. These four locations are depicted in the schematic diagrams of Figure 6 and in the photographs of Figure 7. As indicated in these figures, three of these positions are referred to as "broadside" positions; the fourth is a "downstream" position. 
In the three broadside positions the array plate was parallel to the jet centerline. In the "broadside/far/low" position the array was located $11.28 \mathrm{~m}$ (approx. 22 diameters) from the jet centerline; whereas in the "broadside/close/low" and "broadside/close/high" positions the array was located $8.1 \mathrm{~m}$ (approx. 15.5 diameters) from the jet centerline. In the two "low" positions the array center was $1.35 \mathrm{~m}$ above the ground; while in the "high" position it was $2.52 \mathrm{~m}$ above the ground. In each of the three broadside positions the array was located such that a normal to the center of the array intersected the jet axis $2.74 \mathrm{~m}$ (approx. 5.4 nozzle diameters) downstream of the nozzle exit.

In the downstream position, the array was rotated so that it could sense the jet from a downstream location. As in the broadside locations, the array was located such that a normal to the array intersected the jet centerline $2.74 \mathrm{~m}$ (approx. 5.4 nozzle diameters) downstream of the nozzle exit. The angle between the normal to the array plate and the upstream jet centerline was $126^{\circ}$. As such, the array was close to the peak directivity direction. Post-test analysis revealed that the microphone signals were saturated at all but the lowest power engine operating conditions when the array was at this downstream position. Consequently, data obtained with the array at this position will not be presented in this report.

During the model scale test the microphone array was positioned to maintain geometric similarity with the broadside/close/high position of the full-scale test. The array was located 15.5 diameters $(2 \mathrm{~m}$ at model scale) from the jet centerline and a normal to the array center intersected the jet centerline 5.4 diameters $(0.69 \mathrm{~m}$ at model scale) downstream of the nozzle exit. During the model-scale test the array was positioned so that the center of the array was at the same height as the jet centerline, $3.05 \mathrm{~m}$ above the floor. Figure 8 shows both a schematic representation and a photograph of this arrangement. Since the nozzle diameter of the model was $1 / 4^{\text {th }}$ the size of that of the full-scale engine, maintaining geometric similarity of the array/nozzle position meant that the dimensions of the array were effectively four times bigger relative to the size of the jet during the model scale test vis-àvis the engine test. This relative size difference can be seen in the figures by comparing the size of the array and the nozzle in the broadside/close position depicted in Figure 6 with the array and nozzle size shown Figure 8. Due to this larger effective size, the array was much better suited for identifying details in the jet plume during the model-scale test.

Another significant difference between the two tests is that sound-absorbing wedges were located on the ground between the array and the jet during the model-scale test, but not during the full-scale test. The lack of wedges in the engine test proved detrimental to the full-scale phased array results, especially to those obtained at low frequency. Some of the spectra generated from the full-scale phased array results show low frequency ripples caused by constructive and destructive interference between sound waves coming directly to the array from the jet plume with sound waves reflecting off of the hard ground plane. The ground plane reflection was also responsible for a vertical displacement of the beamform maps about the jet centerline that varied with frequency. Both of these effects - the ripples in the spectra and the vertical displacement of the beamform maps - were less pronounced in the data obtained with the array at the broadside/close/high position. Despite these ground reflections, all three broadside positions provided essentially identical results regarding how the axial location of the peak jet noise source varied with frequency at a given engine operating condition. Consequently, only full-scale data obtained with the array at the broadside/close/high position will be presented in this report.

Unfortunately, the microphone signals obtained with the array at the broadside/close/high position exhibited some evidence of saturation at PLA settings of $102^{\circ}$ and higher. This microphone saturation, however, is not thought to have had a significant impact on the ability of the phased array system to determine the axial location of the sources within the jet plumes. This is based on the observation that the noise source locations changed very little between the broadside/close and the broadside/far array positions even though the degree to which the microphones were saturated did change between these two positions.

\section{Results}

\section{Full-Scale Results}

Figure 9 shows baseline (no chevrons) data obtained with the phased array at the broadside/close/high position at a power lever angle setting of $83^{\circ}$. The data were processed in such a way that the data reduction routine searched for noise sources in a plane which was parallel to the array plate and which passed through the jet axis. The data were reduced into $1 / 12^{\text {th }}$ octave bands over a frequency range from 300 to $20,000 \mathrm{~Hz}$. The complete stack of beamform maps corresponding to this frequency range contained 73 maps. Six beamform maps selected from the complete stack are shown at the right in Figure 9. Beamform maps are shown for $1 / 12^{\text {th }}$ octave bands centered at 500, 1000, 1600, 2500, 5000, and $10000 \mathrm{~Hz}$. The center frequency is shown in the upper left corner of each map. The dynamic range of the contours provided in these and in all the other beamform maps provided in this report is $7 \mathrm{~dB}$, i.e., the peak contour level is $7 \mathrm{~dB}$ higher than the level corresponding to where the contours fade into the background. The plot in the upper left of the figure shows spectra computed from the microphone in the array which measured the median sound level of all the microphones in the array. This median microphone spectrum does not show absolute sound levels along the ordinate. However, the horizontal grid lines in this plot are separated by $5 \mathrm{~dB}$. The plot at the lower left in the figure shows the distance between the peak in the beamform maps and the nozzle exit as a function of frequency, in units of nozzle diameters. This latter line plot will be referred to herein as a peak location plot. Red asterisks have been superimposed on each of these two line 
plots at the frequencies represented by the six beamform maps at the right in the figure.

The microphone spectrum provided in Figure 9 indicates that at this engine power setting the dominant noise source occurred at about $2300 \mathrm{~Hz}$, and the peak location plot shows that this source was located between 1 and 2 nozzle diameters downstream of the nozzle exit. The peak location plot also indicates that the peak source is located about 5 nozzle diameters downstream of the nozzle exit at the lowest processed frequency $(300 \mathrm{~Hz})$, and that the peak source continuously moves closer to the nozzle exit with increasing frequency. For frequencies above about $1500 \mathrm{~Hz}$, the peak source location is always within two nozzle diameters of the nozzle exit. At this engine operating condition the dominant noise sources do not appear to extend significantly in the axial direction. Instead, the noise sources associated with each frequency band tend to be centered about one axial location in the jet plume, although this location does vary with frequency- it gets closer to the nozzle exit with increasing frequency.

Figure 10 shows baseline data processed in the same manner as that provided in Figure 9, but for a higher power lever angle setting of $102^{\circ}$. The PLA $=102^{\circ}$ results presented in Figure 10 are very similar to the PLA $=83^{\circ}$ results of Figure 9. The peak location plots for these two operating conditions are almost identical, indicating virtually no change in how the peak noise location varies with frequency as the engine power is increased between these two operating conditions. In order to provide some indication of the relative strength of the noise sources in the beamform maps, a median microphone spectrum is presented in Figure 10, but the plotted levels are thought to be biased low due to the aforementioned microphone saturation which occurred at PLA settings of $102^{\circ}$ and higher. The main difference between the PLA $=83^{\circ}$ and $\mathrm{PLA}=102^{\circ}$ results is that the peak in the spectrum shifts to a lower frequency for the higher power condition (from about 2300 to $1500 \mathrm{~Hz}$ ). Another difference is that the $1600 \mathrm{~Hz}$ beamform map for the higher power condition shows some evidence of noise coming from both an upstream location (centered about 1.5 nozzle diameters downstream of the nozzle exit) and a downstream location (about 5.5 nozzle diameters downstream of the nozzle). The noise generated downstream in the plume is thought to be broadband shock noise. At $1600 \mathrm{~Hz}$ this broadband shock noise source is about $3 \mathrm{~dB}$ lower than the dominant source closer to the nozzle exit.

The PLA $=83^{\circ}$ and the PLA $=102^{\circ}$ baseline results presented in Figures 9 and 10 were acquired with the engine operating with afterburners off. The results presented in Figure 11 were acquired with the engine operating at the maximum afterburner condition, PLA $=130^{\circ}$. A comparison of the max afterburner results of Figure 11 with the no afterburner results of Figure 10 indicates very little change in how the peak source location varies with frequency between these two conditions. The peak location plot still shows the peak noise source moving toward the nozzle exit as frequency increases, and for frequencies above about $1500 \mathrm{~Hz}$ the peak source is still always within two diameters of the nozzle exit.

The next three figures illustrate how the noise source location results discussed above for the baseline nozzle changed when chevrons were added to the nozzle. Figures 12, 13 , and 14 show a comparison between baseline and chevron data acquired at PLA settings of $83^{\circ}, 102^{\circ}$, and $130^{\circ}$, respectively. Spectra are only provided for the $83^{\circ}$ PLA setting since the spectra corresponding to the two higher power settings are thought to be biased due to microphone saturation. The spectra provided for the $83^{\circ}$ setting indicate a modest broadband reduction $(<1 \mathrm{~dB})$ in the output of the median microphone when chevrons were added to the nozzle as measured at this broadside array location. The peak location plots indicate that for frequencies below $1500 \mathrm{~Hz}$ the chevrons tend to move the peak source location downstream slightly when the engine was operated at the two lower power settings, but show very little change in the noise source location at max power. Overall, these data indicate that the chevrons had a slight impact on the noise source locations when the engine was operated with the afterburners off, but almost no change when the afterburners were on.

The baseline results presented in this section for the three different engine operating conditions indicate that at low frequency $(300 \mathrm{~Hz})$ the peak noise source was located about five nozzle diameters downstream of the nozzle exit and that it moved upstream toward the nozzle as frequency increased. The short distance between the peak source location and the nozzle exit measured here agrees with the full-scale military engine results of Schlinker et al. (Ref. 6), although they found that the peak source remained about 4 to 5 nozzle diameters downstream of the nozzle exit irrespective of frequency. Despite this agreement with the other full-scale engine test, the results presented above were unexpected based on previous model-scale supersonic jet experiments conducted with the Array48 system at the Small Hot Jet Acoustic Rig (SHJAR) at NASA GRC. Some results from these model-scale tests have been presented previously (Ref. 8). The vast majority of these previous studies involved hot and cold subsonic jets and cold supersonic jets. The data obtained during these studies on cold, shock-containing jets tend to exhibit much more character than the full-scale data presented above. In particular, they often show a more complicated behavior regarding how the peak source location in the jet plume varies with frequency.

\section{Model-Scale Results}

In order to better understand the origin of the differences between the full-scale data presented above and the previous model-scale data, another model-scale test was conducted after the completion of the full-scale test. During this test the Array48 system was used to obtain data on the jet flow produced by a $1 / 4^{\text {th }}$ scale model of the F400 series nozzle at the Nozzle Acoustic Test Rig (NATR) at NASA GRC. This 
nozzle was tested in both baseline (no chevrons) and chevron configurations, and the jet was operated at both cold and hot conditions. Table 1 lists the operating conditions set during this test. The hot conditions listed in this table do not mimic any of the engine operating conditions set during the full-scale test. At the corresponding Mach numbers, the full-scale jet flow was always hotter than that produced at model-scale.

As indicated in Table 1, the subscale nozzle was only tested at supersonic conditions. In order to illustrate the differences between a subsonic and a shock-containing jet, Figures 15 and 16 show data obtained during an earlier test at SHJAR involving the Array48 system (Ref. 8). These results were acquired on a $50.8 \mathrm{~mm}$ diameter, round convergent (RC) nozzle (referred to in previous publications as the smc000 nozzle). The array plate was parallel to and $2 \mathrm{~m}$ from the jet axis and the array was centered 10 nozzle diameters downstream of the nozzle exit. The data were processed into $1 / 12^{\text {th }}$ octave bands over a frequency range from 300 to $45000 \mathrm{~Hz}$, yielding stacks containing 87 beamform maps.

Figure 15 shows seven beamform maps selected from a complete stack obtained with the jet operating at $\mathrm{M}_{\text {jet }}=0.89$, $\mathrm{M}_{\mathrm{a}}=1.46$ and $\mathrm{T}_{\mathrm{s}} / \mathrm{T}_{\mathrm{amb}}=2.7$ (referred to in other publications as set point 49). At this subsonic jet Mach number the jet noise is produced solely by the turbulent mixing occurring between the jet and the ambient air. The spectrum at the upper left in the figure shows the broad, haystack-like character expected for turbulent mixing noise in a subsonic jet. Both the peak location plot in the lower left and the beamform maps at the right show the peak noise source moving steadily toward the nozzle exit with increasing frequency. Also notable is that the jet shear layer is visible in the two beamform maps shown at the lower right in the figure; these correspond to the 32 and $40 \mathrm{kHz}$ bands, respectively.

Figure 16 shows $1 / 12^{\text {th }}$ octave band beamform maps computed from data obtained with this RC nozzle generating an underexpanded, cold supersonic jet with $\mathrm{M}_{\text {jet }}=1.4, \mathrm{M}_{\mathrm{a}}=$ 1.4, and $\mathrm{T}_{\mathrm{s}} / \mathrm{T}_{\mathrm{amb}}=1.0$ (set point 9020). The spectrum and the peak location plots provided at the left show distributions for both this supersonic condition (in black) and for the subsonic, $\mathrm{M}_{\text {jet }}=0.9, \mathrm{M}_{\mathrm{a}}=1.46$, and $\mathrm{T}_{\mathrm{s}} / \mathrm{T}_{\mathrm{amb}}=2.7$ condition (in blue) which was presented above in Figure 15 . The 10 points labeled along the black lines correspond to the ten beamform maps provided at the right. The small red squares overlaid on top of the beamform map contours show the approximate axial location of the peak noise source in the jet plume. At low frequency $(<2800 \mathrm{~Hz}$, near point 1$)$ the spectrum for the supersonic jet is very similar to that of the subsonic jet, indicating that turbulent mixing noise is dominant in this frequency range. A fundamental screech tone occurs at $2800 \mathrm{~Hz}$ (point 2) and appears in the beamform maps predominantly as a reflection off of the upstream nozzle hardware. At $5600 \mathrm{~Hz}$ (point 4) the first harmonic of the fundamental screech tone comes from a location in the jet plume about 5.5 diameters downstream of the nozzle exit.

Broadband shock noise (BBSN) shows up clearly in the supersonic spectra shown in Figure 16 as the elevated region above $6300 \mathrm{~Hz}$ (to the right of point 5). A dominant BBSN hump is visible in the spectrum between 6300 and $11000 \mathrm{~Hz}$ (between points 5 and 8). BBSN humps such as this are thought to be created by large scale turbulent structures passing through the shocks. Note that the location of the peak noise source gradually moves downstream as frequency increases through the BBSN hump (between points 5 and 8). This is visible in both the peak location plot and in the beamform maps. Once the frequency is increased beyond the BBSN hump (between points 8 and 9), the peak location jumps back upstream. In a cold supersonic jet emanating from a nozzle which does not contain chevrons, the peak location tends to remain near this upstream location over a wide frequency range (to the right of point 9), unless this region contains another BBSN hump. The peak location plot presented in Figure 16 for the supersonic jet suggests that there may be a second BBSN hump at about $15000 \mathrm{~Hz}$.

The BBSN data presented in Figure 16 indicate that there is a distinct difference in behavior regarding how the location of the peak noise source varies with increasing frequency depending on whether or not this variation occurs through a BBSN hump. The peak source location moves downstream when the frequency is increased through a hump; it does not move downstream when the frequency increase occurs in the elevated region of BBSN outside the humps. This difference in behavior suggests that there may be two different mechanisms creating the elevated region of BBSN. The BBSN humps are thought to be created by turbulent eddies which are large enough to span more than one shock cell. The interaction of these large eddies with the shocks generates highly correlated noise radiating from multiple shocks simultaneously. The BBSN associated with the regions outside the humps appears to be generated by turbulent eddies which are smaller than the shock spacing. This turbulence/shock cell interaction produces uncorrelated noise radiating from the individual shock cells. The beamform map at the lower right of Figure 16 (\#10), shows high frequency noise coming from individual shock cells in the jet plume.

The remainder of this section will focus on results obtained from the test of the $1 / 4^{\text {th }}$ scale model of the F400 nozzle that was conducted at GRC after the completion of the full-scale engine test. Figure 17 shows source location data obtained from two cold supersonic jets produced by this nozzle. Data are provided for two conditions, $\mathrm{M}_{\text {jet }}=1.22, \mathrm{~T}_{\mathrm{s}} / \mathrm{T}_{\mathrm{amb}}=0.77$ (in blue on the line plots and in the left column of beamform maps) and $\mathrm{M}_{\text {jet }}=1.47, \mathrm{~T}_{\mathrm{s}} / \mathrm{T}_{\mathrm{amb}}=0.73$ (in black on the line plots and in the right column of beamform maps). Both of these represent overexpanded conditions. As might be expected, the peak location plots show that the dominant low frequency turbulent mixing noise is produced further downstream in the higher speed jet vis-à-vis the lower speed jet (points 1 to 3 ). Like the supersonic data shown above for the RC nozzle, each of the microphone spectra show a dominant BBSN hump, and the corresponding line plots and beamform maps show the peak source moving downstream as the frequency increases through the humps (points 7 to 9 in the 
Mach 1.22 jet, and points 5 to 7 in the Mach 1.47 jet). Also like the RC nozzle data, the peak source location in each jet jumps back upstream when the frequency is increased beyond the hump. At frequencies higher than the humps the peak source location in each jet jumps back and forth between individual shock cells, but remains close to the same axial location (about 5 nozzle diameters downstream) over a wide frequency range.

Figure 18 shows source location results for two Mach 1.22 jets, one cold $\left(\mathrm{T}_{\mathrm{s}} / \mathrm{T}_{\mathrm{amb}}=0.77\right)$ and one hot $\left(\mathrm{T}_{\mathrm{s}} / \mathrm{T}_{\mathrm{amb}}=2.16\right)$. This cold condition data was also presented above in Figure 17. The peak location plots for these two different temperatures are nearly identical at low frequency (points 1 to 6 ), indicating that the location of the source of low frequency turbulent mixing noise changes very little with increasing jet temperature. Unlike with the cold jet, however, the spectrum for the hot jet does not show a BBSN hump, and neither the peak location plot nor the beamform maps provided for the hot jet show the peak source location moving downstream with increasing frequency over any part of the frequency range. Instead, both the spectrum and the peak location plots of the hot jet resemble those of a subsonic jet in which only turbulent mixing noise is present. These results suggest that either heat has been added to the jet to the point that the BBSN hump has been masked by turbulent mixing noise, or that the mechanism responsible for generating the hump (large scale turbulent structures crossing the shocks) has been disrupted. Particle Image Velocimetry data obtained on similar jets (cold vs. hot shock-containing jets of the same Mach number) indicate that the addition of heat has very little effect on shock structure (Ref. 13). This suggests that the first scenario is more likely that the BBSN hump is being masked by turbulent mixing noise. However, it is still possible that the added heat altered the turbulent structures in such a way that the eddy/shock interaction produced less BBSN.

Figure 19 shows the effect of adding heat to the cold Mach $=1.47$ jet produced by the $1 / 4^{\text {th }}$ scale nozzle. This figure shows results for both the cold $\left(\mathrm{T}_{\mathrm{s}} / \mathrm{T}_{\mathrm{amb}}=0.73\right)$ condition presented above in Figure 17 and for a hot condition $\left(\mathrm{T}_{\mathrm{s}} / \mathrm{T}_{\mathrm{amb}}\right.$ $=2.45$ ). Like the results presented above in Figure 18 for the lower Mach number, the location of the source of the low frequency turbulent mixing noise changes very little with increasing jet temperature (indicated by the overlap of the peak location plots at points 1 and 3). Unlike the lower Mach number results, however, both the cold and hot data obtained at this higher Mach number show a dominant BBSN hump and the movement of the peak source location downstream as frequency increases through the humps. In this case it appears that the addition of heat did not increase the turbulent mixing noise to the point that it masked the BBSN hump. Despite this common feature of the two spectra, these data do show a noticeable difference in where the high frequency noise to the right of the humps comes from inside the plume. In the cold jet it is produced by turbulence passing through shocks located relatively far (about 5 nozzle diameters) downstream. In the hot jet it is also produced by turbulence passing through shocks, but the peak source rapidly approaches the nozzle exit as the frequency is increased, jumping from one shock to another along the way.

Figure 20 shows the effect of adding chevrons to the $1 / 4^{\text {th }}$ scale CD nozzle for a cold $\left(T_{s} / T_{\text {amb }}=0.77\right)$, overexpanded jet at Mach 1.22. This is the same baseline (no chevron) data that was shown above in Figures 17 and 18. As shown in Figure 20, the spectra, the peak location plots and the beamform maps for the baseline and chevron cases are almost identical, indicating that the chevrons have almost no effect on either the noise levels or on the noise source locations at this combination of jet operating condition and array position (broadside to the jet).

Figure 21 shows another no chevron/chevron comparison for two cold jets $\left(\mathrm{T}_{\mathrm{s}} / \mathrm{T}_{\mathrm{amb}}=0.70\right)$, but at a higher Mach number, $\mathrm{M}_{\mathrm{jet}}=1.47$. A comparison of these results with those obtained at the lower Mach number $\left(\mathrm{M}_{\mathrm{jet}}=1.22\right.$ shown in Figure 20) indicates that the chevrons had a much bigger impact on the noise produced by the jet at this higher Mach number. The spectra show a low frequency broadband noise benefit associated with using the chevrons and a reduction in amplitude of the screech tones, but the peak of the BBSN hump increases in amplitude and shifts to a higher frequency when the chevrons are added. The source location data show the peak source location slightly further downstream (11 nozzle diameters versus 10) at the high frequency edge of the hump (just to the right of point 7 in the line plots). There is also a noticeable difference regarding where the high frequency noise just to the right of the humps comes from in the plume (points 8 and 9). The peak source of this noise is located much further downstream in the chevron case ( 8 to 9 nozzle diameters downstream vs. 5). The beamform maps shown at the bottom of the Figures 9 to 11 indicate that the high frequency BBSN is more evenly distributed across the shocks in the jet plume in the chevron case, despite the fact that the noise levels are almost identical in the two cases (points 8 to 11 in the spectra).

Figure 22 shows a chevron/no chevron comparison for two hot jets $\left(\mathrm{T}_{\mathrm{s}} / \mathrm{T}_{\mathrm{a}}=1.86\right)$ at Mach 1.22. Like the results presented in Figure 20 which showed a no chevron/chevron comparison at this jet Mach number at cold conditions, the Figure 22 results show that the chevrons had very little effect on the noise produced by the jet as measured with the array at this broadside location. Overall, the spectrum is slightly lower (about $1 \mathrm{~dB}$ ) for the chevron case, but there is almost no shift in where the noise sources are located in the jet plume.

Figure 23 shows the effect of adding chevrons to a hot jet $\left(\mathrm{T}_{\mathrm{s}} / \mathrm{T}_{\mathrm{a}}=1.80\right)$ at a higher Mach number $\left(\mathrm{M}_{\mathrm{jet}}=1.47\right)$. Like the cold jet results presented above, a comparison of the data obtained at the two Mach numbers (Figs. 22 and 23) indicates that the chevrons have a bigger impact on the peak noise source locations at the higher Mach number. As shown in Figure 23 both the baseline and no chevron spectra show what appear to be small BBSN humps, but only the baseline source location data show the peak noise source location moving downstream as frequency increases through the hump. The 
beamform maps provided for the baseline nozzle indicate that the BBSN hump is created by noise generated between 7 and 10 nozzle diameters downstream of the nozzle exit (points 5 to 8). The corresponding maps for the chevron nozzle suggest that the BBSN generated in this part of the jet is being masked by a stronger source close to the nozzle exit. This upstream source may be stronger in the chevron case due to turbulence introduced into the flow just downstream of the nozzle exit by the chevrons. This added turbulence also seems to be responsible for the increased levels of high frequency noise evident in the microphone spectra computed from the data obtained with the chevrons installed (points 9 to 11 ).

\section{Interpretation of the Full-Scale Results Based on the Model-Scale Test}

As mentioned above, the test involving the $1 / 4^{\text {th }}$ scale model of the F400 nozzle was conducted in order to determine the origin of the differences between the full-scale results and previous model-scale results obtained on cold, shockcontaining jets. The spectra of cold, shock-containing jets tend to show separate regions dominated by turbulent mixing noise, screech and broadband shock noise, and the corresponding source location data tend to show a rather complicated behavior in which the peak source location moves upstream, then downstream, then upstream again as frequency increases. In contrast, the full-scale results show little evidence of shock noise and the peak source location always moves upstream toward the nozzle exit as frequency increases. Instead of looking like the results of a cold, shock-containing jet, the full-scale results tend to resemble a simple subsonic jet in which only turbulent mixing noise is present.

The results presented above from the test at the NATR involving the $1 / 4^{\text {th }}$ scale nozzle provide some insights regarding why the full-scale results have this simple character. These model-scale results show that it is possible to start with a cold shock-containing jet and add heat and turbulence until the resulting spectra and source location data begin to resemble those of the full-scale engine. In particular, the hot, high Mach number, chevron results presented in Figure 23 are quite similar to the full-scale data. They show the downstream sources of BBSN (which must also be present in the full-scale overexpanded jets) masked by a stronger source closer to the nozzle exit. At model scale it appears that this upstream source is dominant because 1) the added heat increases the jet velocity which leads to an increase in the jet turbulence kinetic energy, which, in turn, tends to increase the turbulent mixing noise, and 2) the chevrons add turbulence to the flow just downstream of the nozzle exit. At full-scale the upstream source dominates even when chevrons are not installed on the nozzle. As mentioned above, at similar Mach numbers the full-scale jets were always hotter than those tested at modelscale. Apparently, the upstream source dominates in the fullscale baseline application because the flow coming out of the engine is hotter and, hence, has a higher velocity and a higher turbulence kinetic energy than the flows tested at model scale.

\section{Recommendations}

The test on the F404 engine provided some valuable insights regarding how future source localization tests of fullscale military engines could be improved. The following recommendations should be implemented before another fullscale test of this type is conducted:

1) Efforts should be made to reduce the adverse effects of the ground reflections. This can be achieved by installing sound absorbing acoustic wedges between the jet plume and the array or by positioning the array on the ground either under or off to the side of the jet.

2) A bigger array should be used in order to improve the ability of the array to identify details in the jet plume. At the broadside/close/high position for which most of the full-scale engine data were acquired, the Array48 system did not offer sufficient spatial resolution to identify the noise produced by individual shock cells. Assuming a new array placed at the same location (15.5 nozzle diameters away from the jet centerline), its dimensions would have to be four times greater than those of the Array48 system in order to provide the same spatial resolution as that offered by the experimental setup used during the $1 / 4^{\text {th }}$ scale model test.

3) The array microphones should be replaced with less sensitive piezoresistive transducers that will not saturate when the array is located close to the jet plume and the engine is operating at high power conditions.

4) The solid array plate should be replaced with an open framework of thin, connected beams which would hold the transducers firmly in place. This open framework will make the array less susceptible to vibration due to the high acoustic loads encountered when the array is located near the jet.

A final recommendation concerns the need to document the characteristics of the turbulence produced by full-scale military engines. The results presented above suggest that the flow exiting the full-scale nozzle was more turbulent than the model-scale flow. Higher turbulence levels could be expected due to the higher jet temperatures at full-scale. It is also possible that the full-scale jet flow was more turbulent due to the more complicated flow path inside the engine. In order to develop noise reduction technologies for full-scale engines during model-scale tests it may be necessary for the model scale flow characteristics to more closely match those of the full-scale engine. At present, however, the characteristics of the turbulent flow exiting the full-scale engine are unknown. Therefore, they should be measured using a technique such as Particle Image Velocimetry. 


\section{Summary}

1) Data were acquired with the Array48 phased array system on a F404 engine over a wide range of operating conditions, including with afterburners on. The full-scale engine source localization results tend to have a simple character. The data obtained at the different operating conditions all show the peak source located about five nozzle diameters downstream of the nozzle exit at low frequency $(300 \mathrm{~Hz})$, and moving continuously toward the nozzle exit as frequency increases. The full-scale engine data obtained with the phased array show little evidence of broadband shock noise.

2) A comparison of full-scale engine data obtained with and without chevrons installed on the nozzle indicates that for frequencies below $1500 \mathrm{~Hz}$ the chevrons moved the peak source location slightly further downstream when the engine was operated at the two lower power settings, but had very little effect at full power. The data obtained with the array broadside to the jet also indicate that the chevrons reduced the broadband jet noise slightly $(<1 \mathrm{~dB})$ at the $\mathrm{PLA}=83^{\circ}$ setting. The noise reduction potential of the chevrons could not be determined using the array microphones at the two higher power settings due to microphone saturation.

3) The model-scale results tend to exhibit much more character than the full-scale results. The spectra of cold, shock-containing jets tend to show separate regions dominated by turbulent mixing noise, screech and broadband shock noise, and the corresponding source location data tend to show a rather complicated behavior in which the peak source location moves upstream, then downstream, then upstream again as frequency increases.

4) The model-scale results indicate a distinct difference in behavior regarding how the location of the peak source varies as frequency increases depending on whether or not the frequency variation occurs within a BBSN hump. The peak source location tends to move downstream when the frequency increase occurs through a BBSN hump. It does not move downstream if the frequency increase is not through a hump. This difference in behavior suggests that there may be two different mechanisms responsible for producing the BBSN.

5) The model-scale results obtained on the $1 / 4^{\text {th }}$ scale model F400 nozzle show that it is possible to start with a cold, shock-containing jet and add heat and turbulence until the resulting spectra and source location data begin to resemble those of the full-scale engine. This suggests that the differences between the full-scale and previous model scale results are due to the hotter nozzle exit flows in the full-scale test.
6) The inability of the model-scale tests to mimic the very hot flows of the full-scale nozzle flow may be hindering efforts to develop noise reduction concepts for military engines at model scale.

\section{References}

1. "Acquisition Safety-Noise Control Aboard Navy Ships," Naval Safety Center, 26 August 2009. Web. 10 November 2009.

2. Humes, L.E., Joellenbeck, L.M., Durch, J.S., (ed.) Noise and Hearing Loss: Implications for Hearing Loss and Tinnitus, Washington, DC. National Academies Press, 2006.

3. Shaw, G.B., and Trost, R.P., "Statistical Analysis of Hearing Loss Among Navy Personnel," CRM D0011228.A2/Final, February 2005.

4. Norum, T.D., Garber, D.P., Golub, R.A., Santa Maria, O.L., Orme, J.S., "Supersonic Jet Exhaust Noise at High Subsonic Flight Speed," NASA/TP_-2004-212686, January 2004.

5. Gee, K.L., Gabrielson, T.B., Atchley, A.A., Sparrow, V.W., "Preliminary Analysis of Nonlinearity in Military Jet Aircraft Noise Propagation," AIAA Journal, Vol. 43, No. 6, June 2005.

6. Schlinker, R.H., Liljenberg, S.A., Polak, D.R., Post, K.A., Chipman, C.T., Stern, A.M., "Supersonic Jet Noise Source Characteristics \& Propagation: Engine and Model Scale," AIAA paper 2007-3623, May 2007.

7. Martens, S., Spyropoulos, J.T., "Practical Jet Noise Reduction for Tactical Aircraft," ASME paper GT201023699, June 2010.

8. Dougherty, R.P., Podboy, G.G. "Improved Phased Array Imaging of a Model Jet," AIAA paper 2009-3186, May 2008.

9. Walton, J.T., Burcham, F.W., "Exhaust-Gas Pressure and Temperature Survey of F404-GE-400 Turbofan Engine," NASA TM-88273, December 1986.

10. Huber, J., Vincent Fleury, J.B., Britchford, K., Laurendeau, E., Long, D., "Understanding and Reduction of Cruise Jet Noise at Model and Full Scale," AIAA paper 2009-3382, May 2009.

11. Mengle, V.G., Ganz, U.W., Nesbitt, E., Bultemeier, E.J., Thomas, R.H., "Flight Test Results for Uniquely Tailored Propulsion-Airframe Aeroacoustic Chevrons: Shockcell Noise," AIAA paper 2006-2439, May 2006.

12. Soeder, R.H., Wnuk, S.P., Loew, R.A., "Nozzle Acoustic Test Rig User Manual," NASA/TM-2006-212939, November 2006.

13. Bridges, James "Broadband Shock Noise in InternallyMixed Dual-Stream Jets," AIAA Paper AIAA-20093210, May 2009. 
TABLE $1 .-$ FLOW CONDITIONS DURING THE $1 / 4^{\mathrm{TH}}$ SCALE MODEL TEST

\begin{tabular}{|c|c|c|c|c|c|c|c|}
\hline Configuration & $\mathrm{M}_{\text {iet }}$ & $\mathrm{T}_{\mathrm{s}} / \mathrm{T}_{\mathrm{amb}}$ & $\mathrm{M}_{\mathrm{a}}$ & $\mathrm{P}_{\mathrm{t} \text { core }} / \mathrm{P}_{\mathrm{amb}}$ & $\mathrm{P}_{\mathrm{t} \text { bvpass }} / \mathrm{P}_{\mathrm{amb}}$ & $\mathrm{T}_{\mathrm{t} \text { core }} / \mathrm{T}_{\mathrm{amb}}$ & $\mathrm{T}_{\mathrm{t} \text { bvpass }} / \mathrm{T}_{\mathrm{amb}}$ \\
\hline Baseline & 1.22 & 0.77 & 1.07 & 2.50 & 2.51 & 0.99 & 1.00 \\
\hline Baseline & 1.47 & 0.73 & 1.23 & 3.52 & 3.52 & 1.00 & 0.99 \\
\hline Baseline & 1.23 & 1.86 & 1.67 & 2.50 & 2.50 & 2.80 & 1.04 \\
\hline Baseline & 1.48 & 1.80 & 1.97 & 3.51 & 3.51 & 3.00 & 1.05 \\
\hline Chevron & 1.22 & 0.79 & 1.09 & 2.50 & 2.50 & 1.03 & 1.00 \\
\hline Chevron & 1.47 & 0.70 & 1.23 & 3.50 & 3.59 & 1.01 & 1.00 \\
\hline Chevron & 1.23 & 1.87 & 1.67 & 2.49 & 2.49 & 2.80 & 1.05 \\
\hline Chevron & 1.48 & 1.80 & 1.97 & 3.51 & 3.50 & 3.00 & 1.05 \\
\hline
\end{tabular}

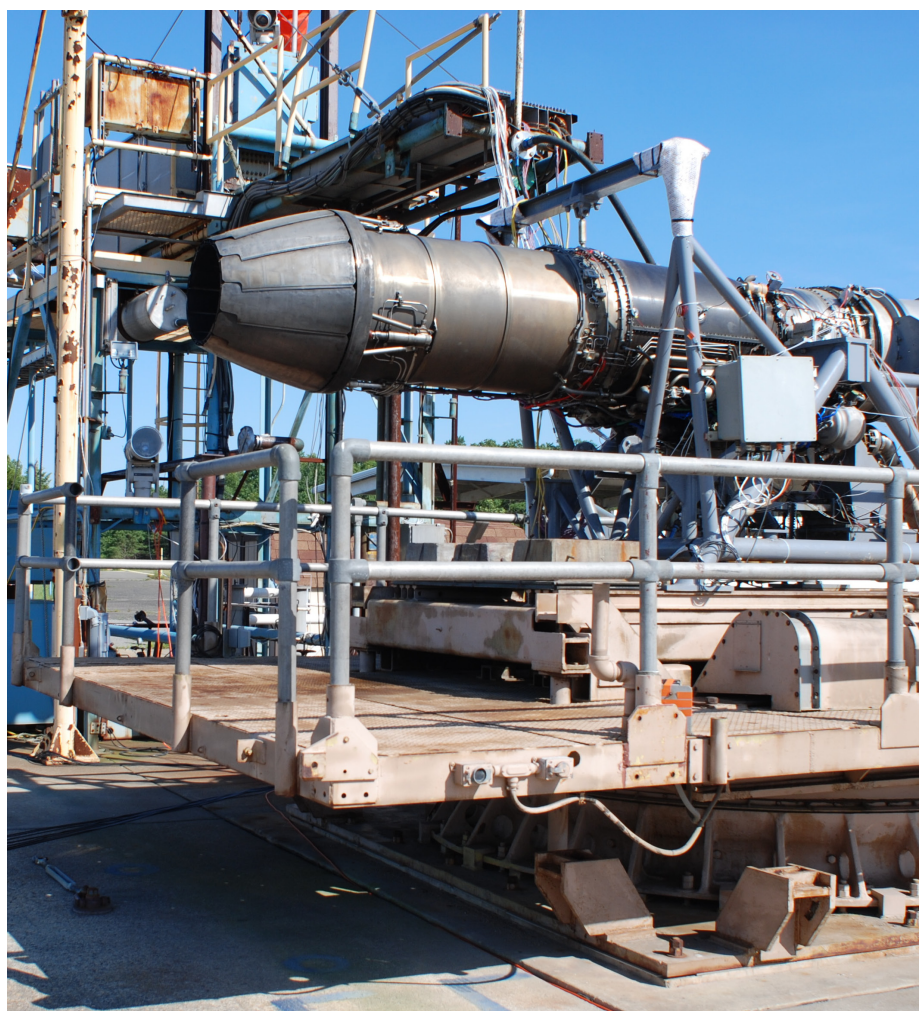

Figure 1.-Photo of the full-scale F404-GE-F400 engine mounted at the Outdoor Test Stand at the Naval Air Engineering Station. 


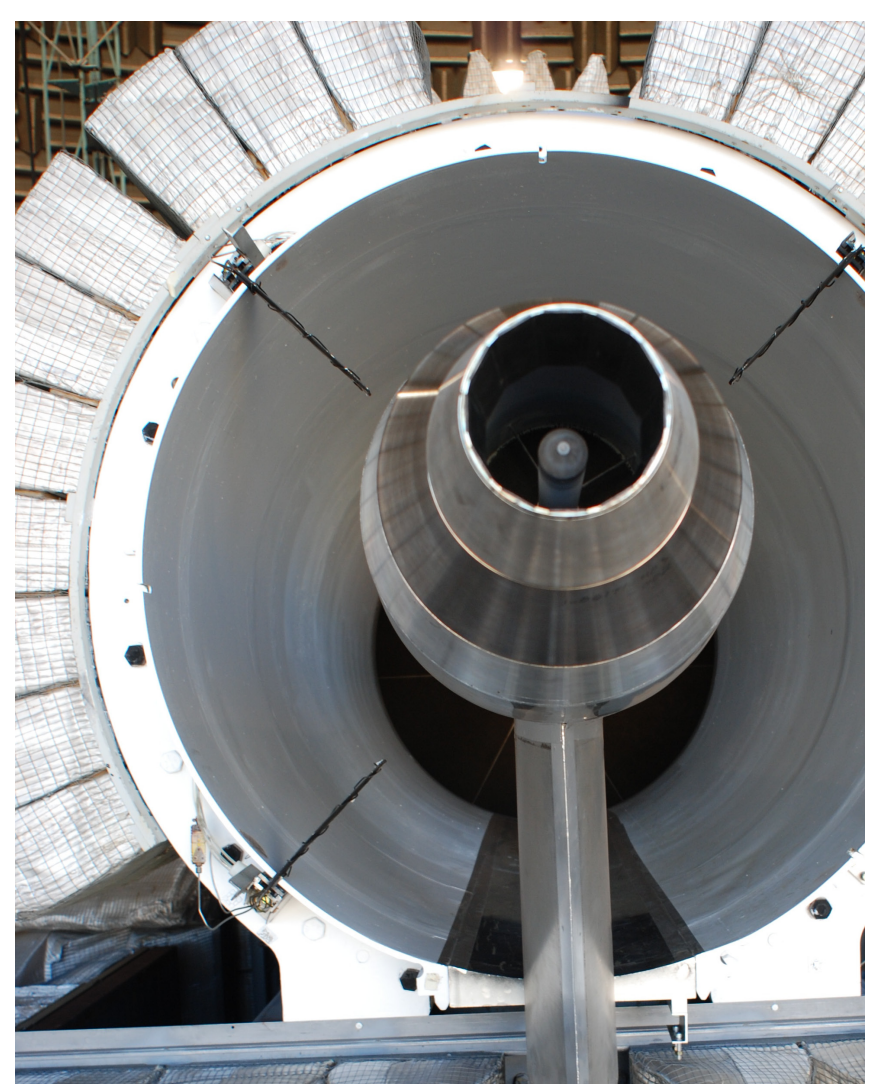

Figure 2.-Photo of the $1 / 4^{\text {th }}$ scale F400 nozzle mounted to the High Flow Jet Exit Rig at the Nozzle Acoustic Test Rig at NASA GRC. The nozzle is shown in the baseline (no chevron) configuration.

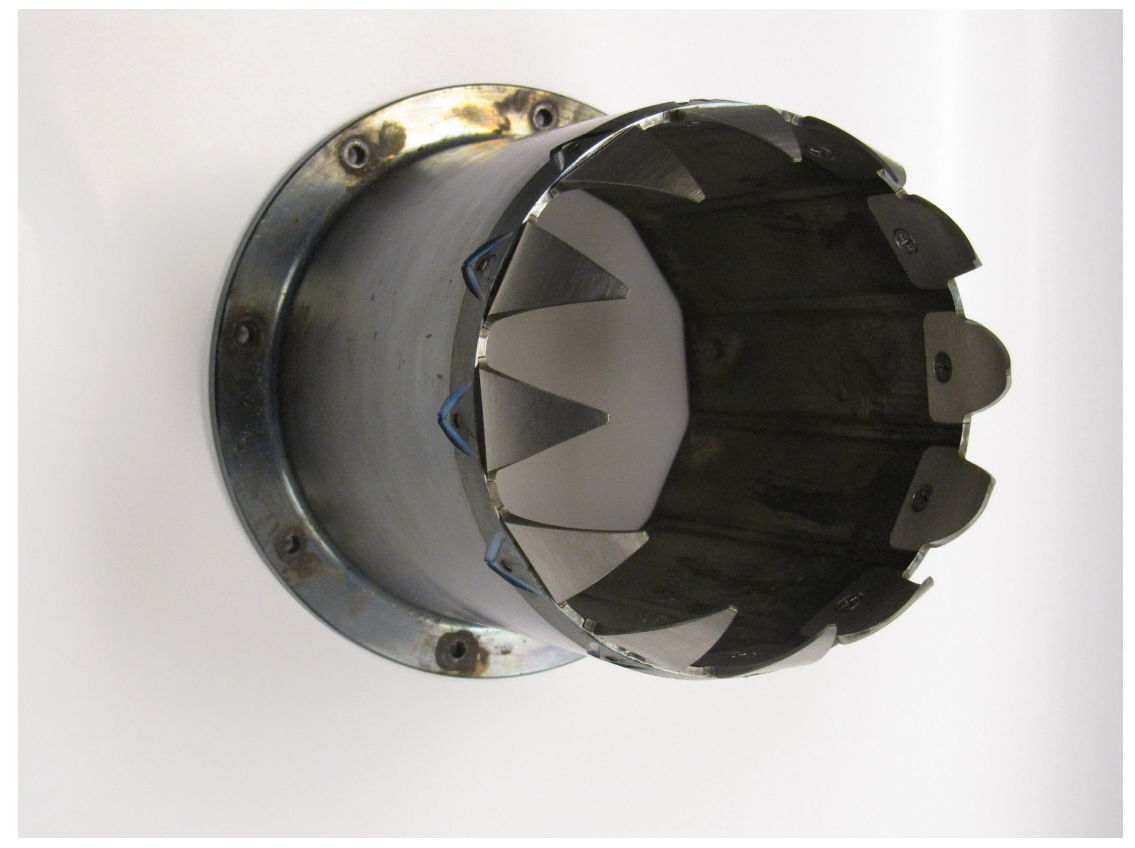

Figure 3.-Photo showing chevrons attached to the $1 / 4^{\text {th }}$ scale F400 nozzle. 

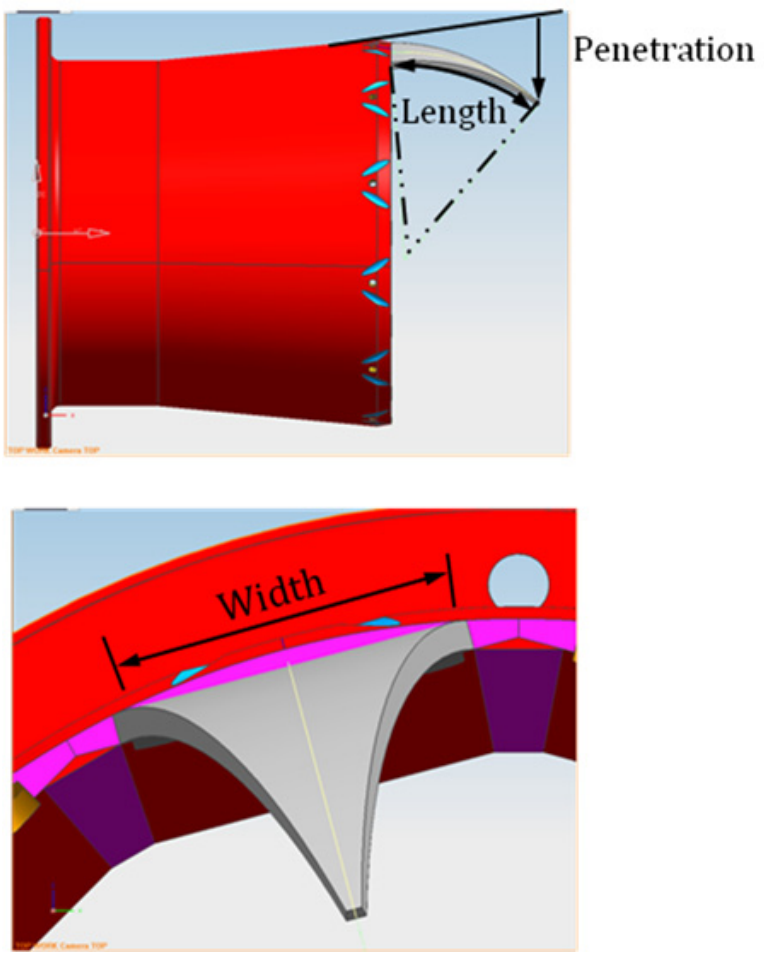

Figure 4.-Schematics illustrating definitions of chevron penetration, length and width.
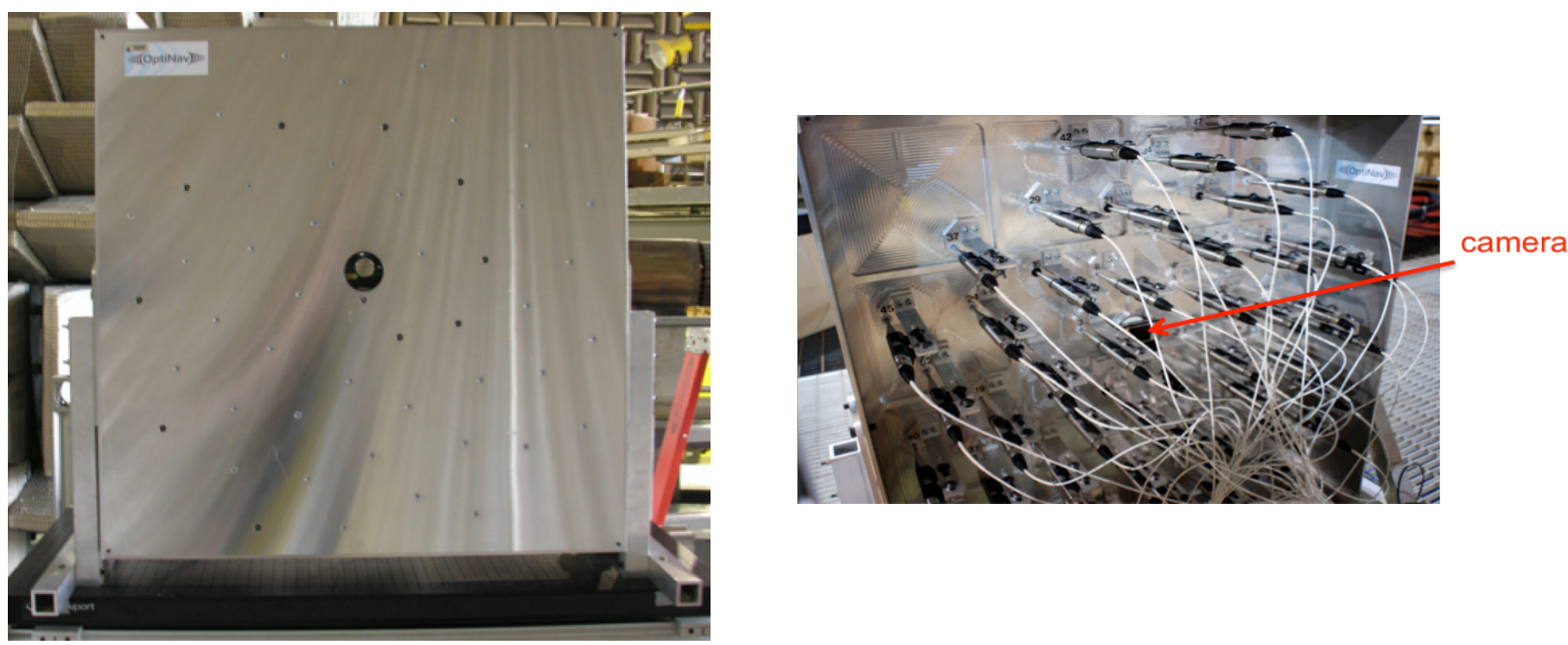

Figure 5.-Photo showing front (left) and rear (right) views of Array48 phased array system. 


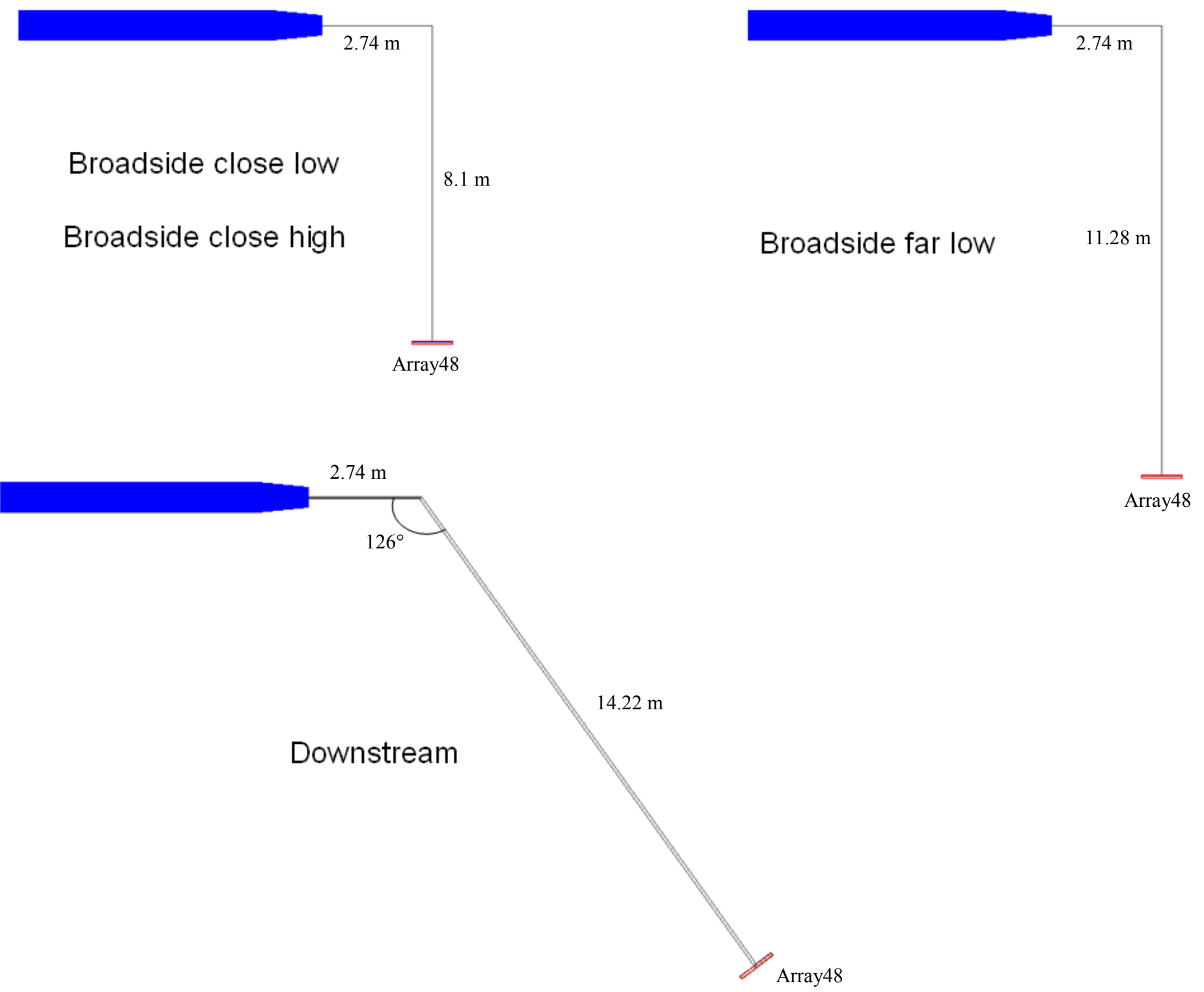

Figure 6.-Schematic diagrams showing phased array positions during the full-scale engine test. 


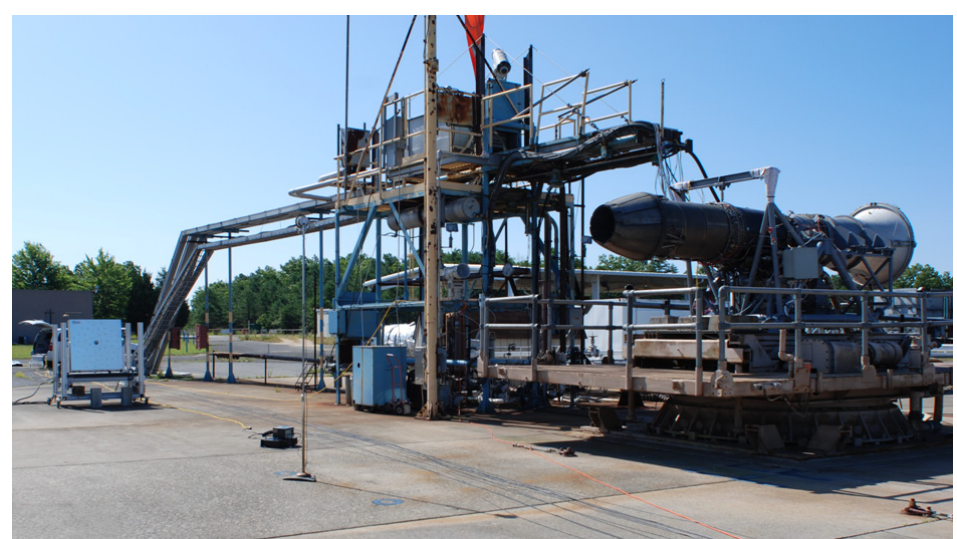

Broadside far low position (array center $1.35 \mathrm{~m}$ above the ground)

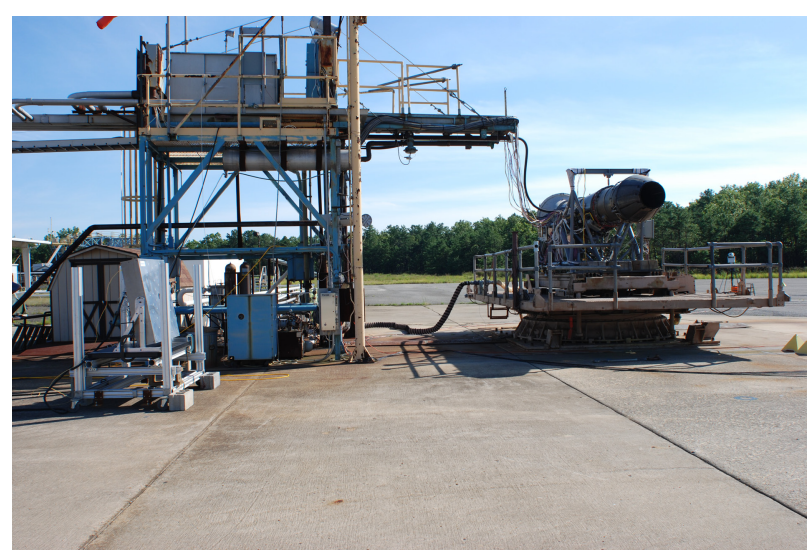

Broadside close low position (array center $1.35 \mathrm{~m}$ above the ground)

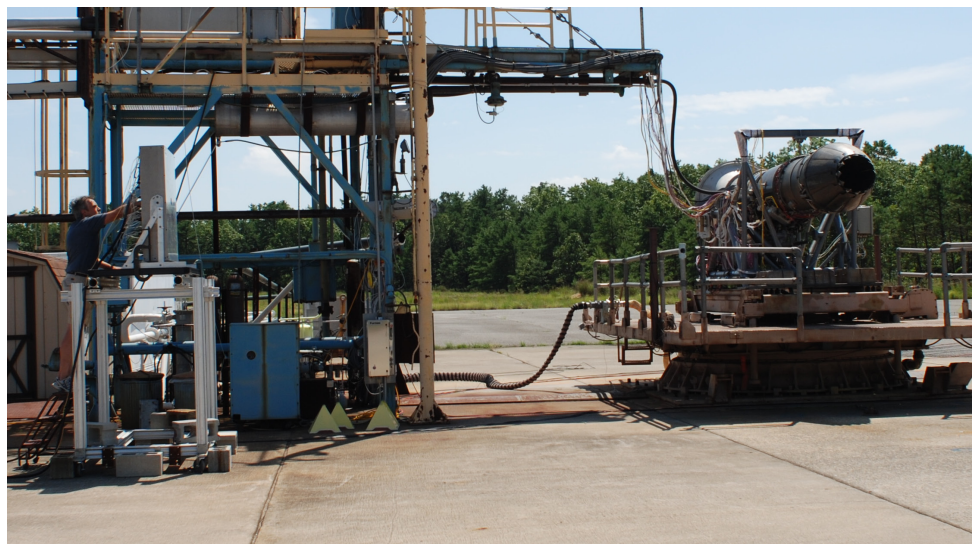

Broadside close high position (array center $2.52 \mathrm{~m}$ above the ground)

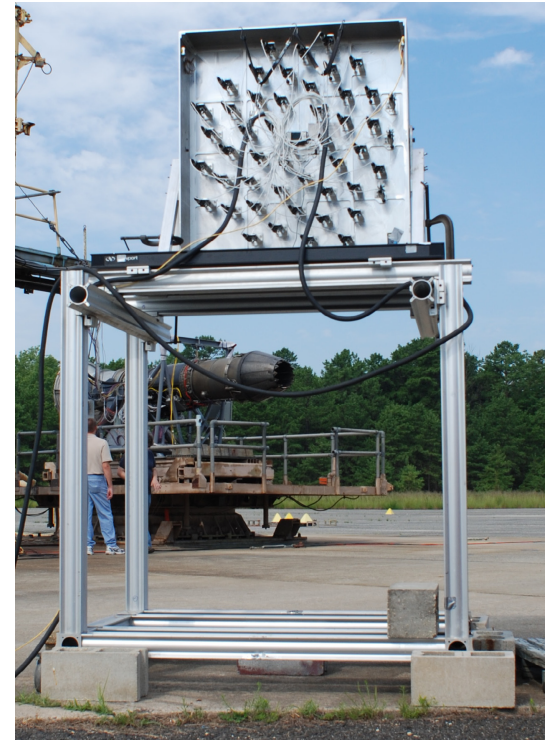

Downstream position

Figure 7.-Photographs of Array48 at the four test positions during the full-scale engine test. 

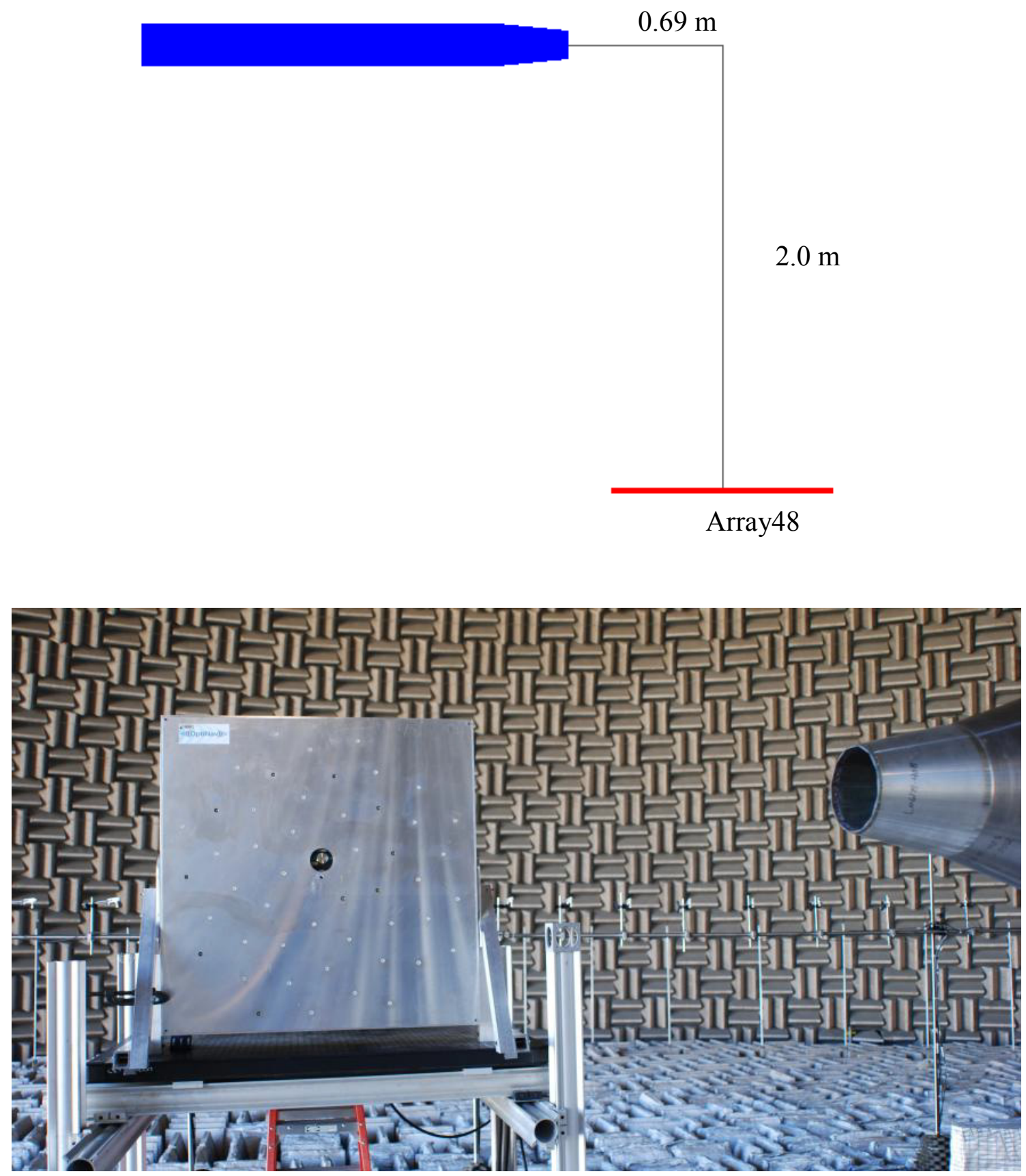

Figure 8.-Schematic (top) and photograph (bottom) of microphone array deployment during the modelscale test at the Nozzle Acoustic Test Rig. 

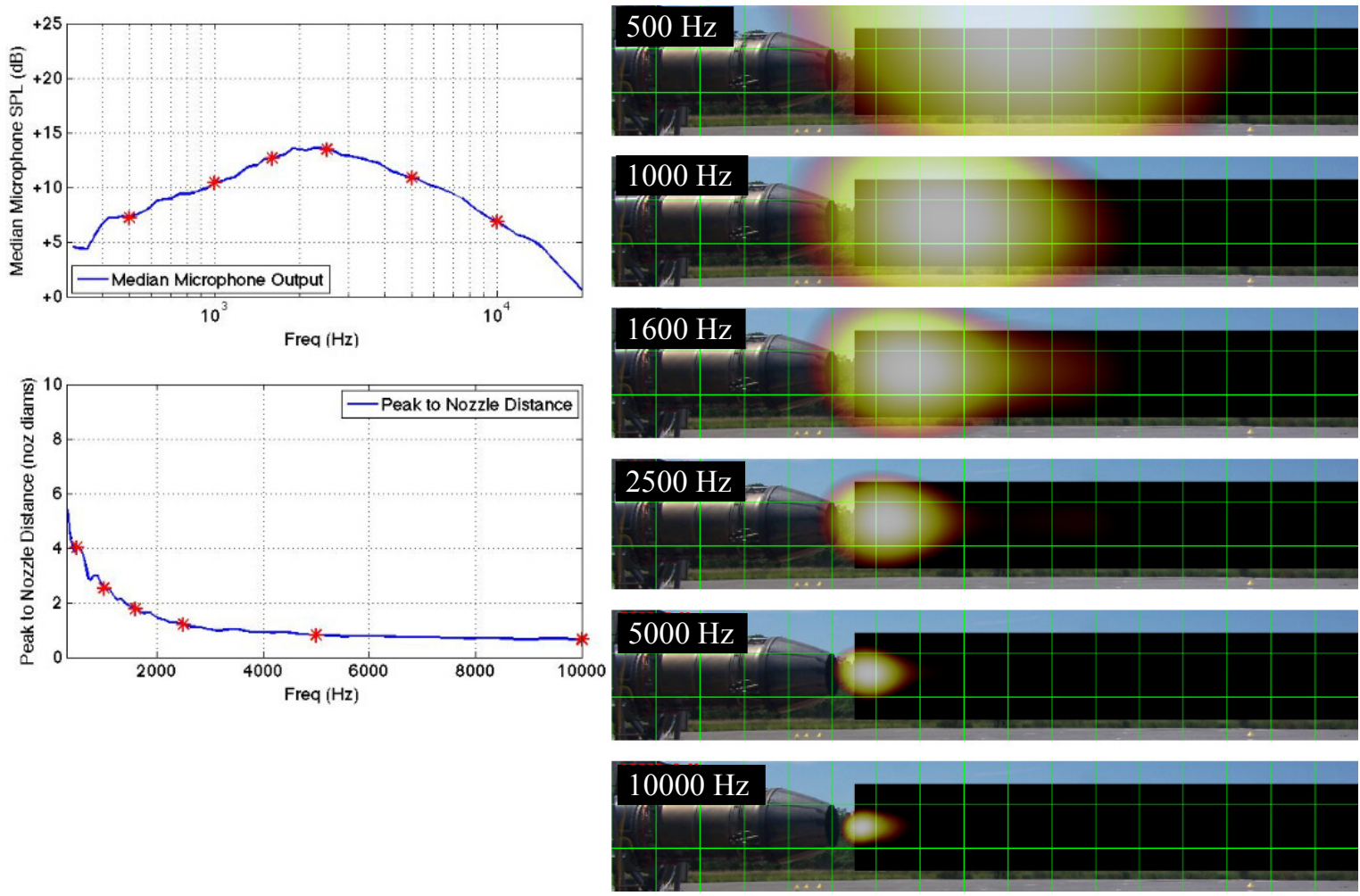

Figure 9.-Median mic spectra (upper left), peak location plot (lower left), and beamform maps for the full-scale engine operating at PLA $=83^{\circ}$.
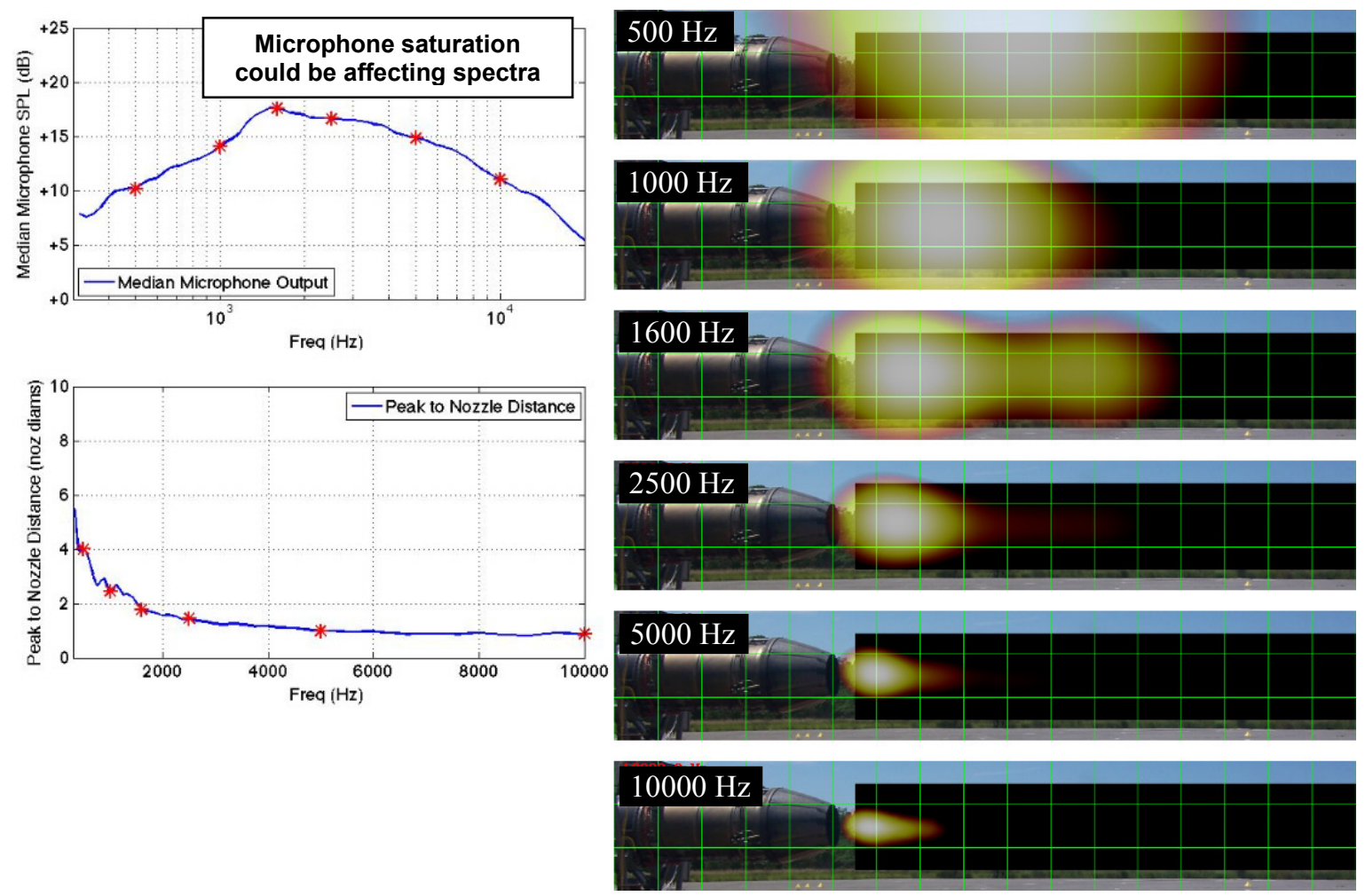

Figure 10.-Median mic spectra (upper left), peak location plot (lower left), and beamform maps for the full-scale engine operating at $\mathrm{PLA}=102^{\circ}$ ( $\max$ non afterburning condition). 

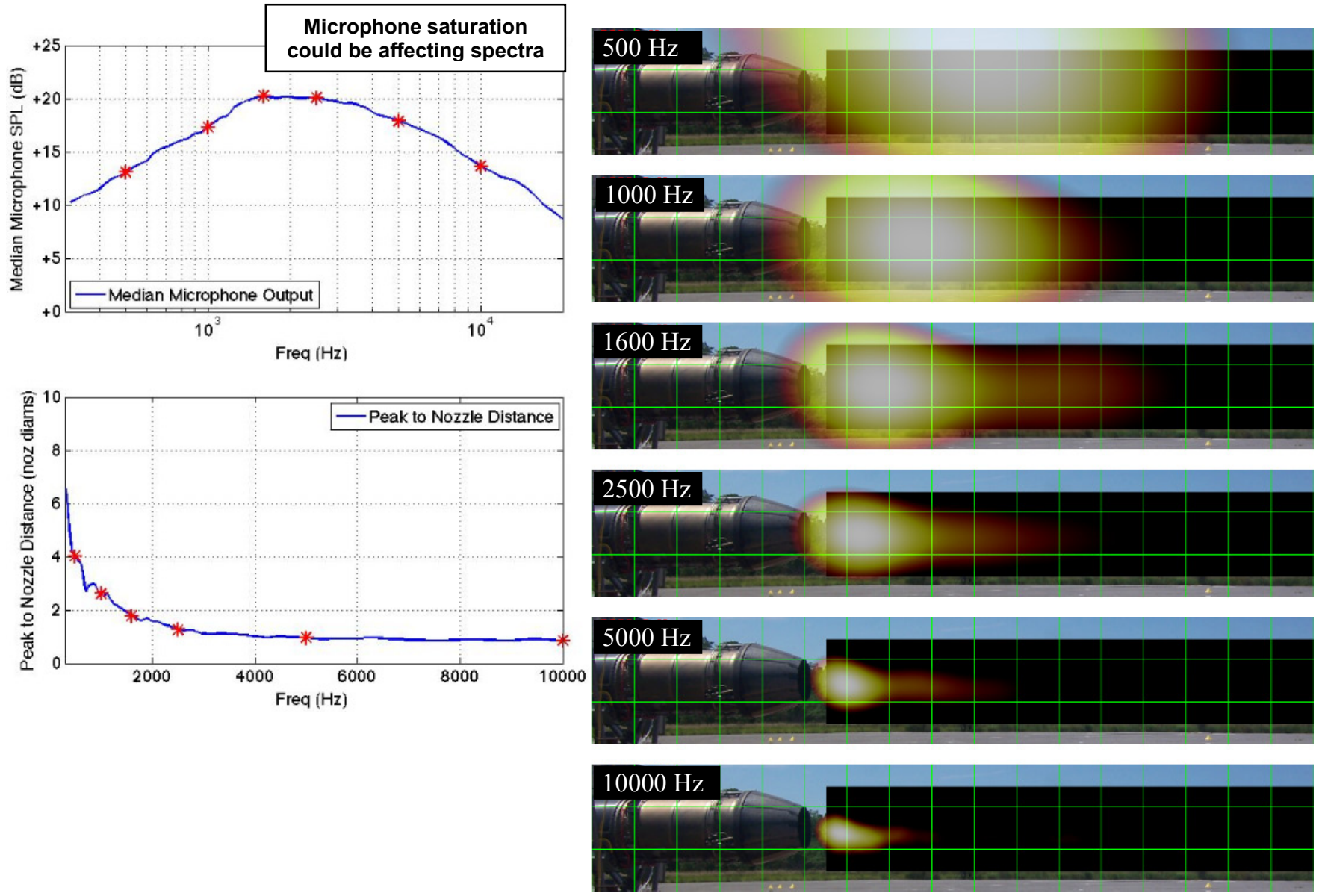

Figure 11.-Median mic spectra (upper left), peak location plot (lower left), and beamform maps for the full-scale engine operating at max afterburner condition. 

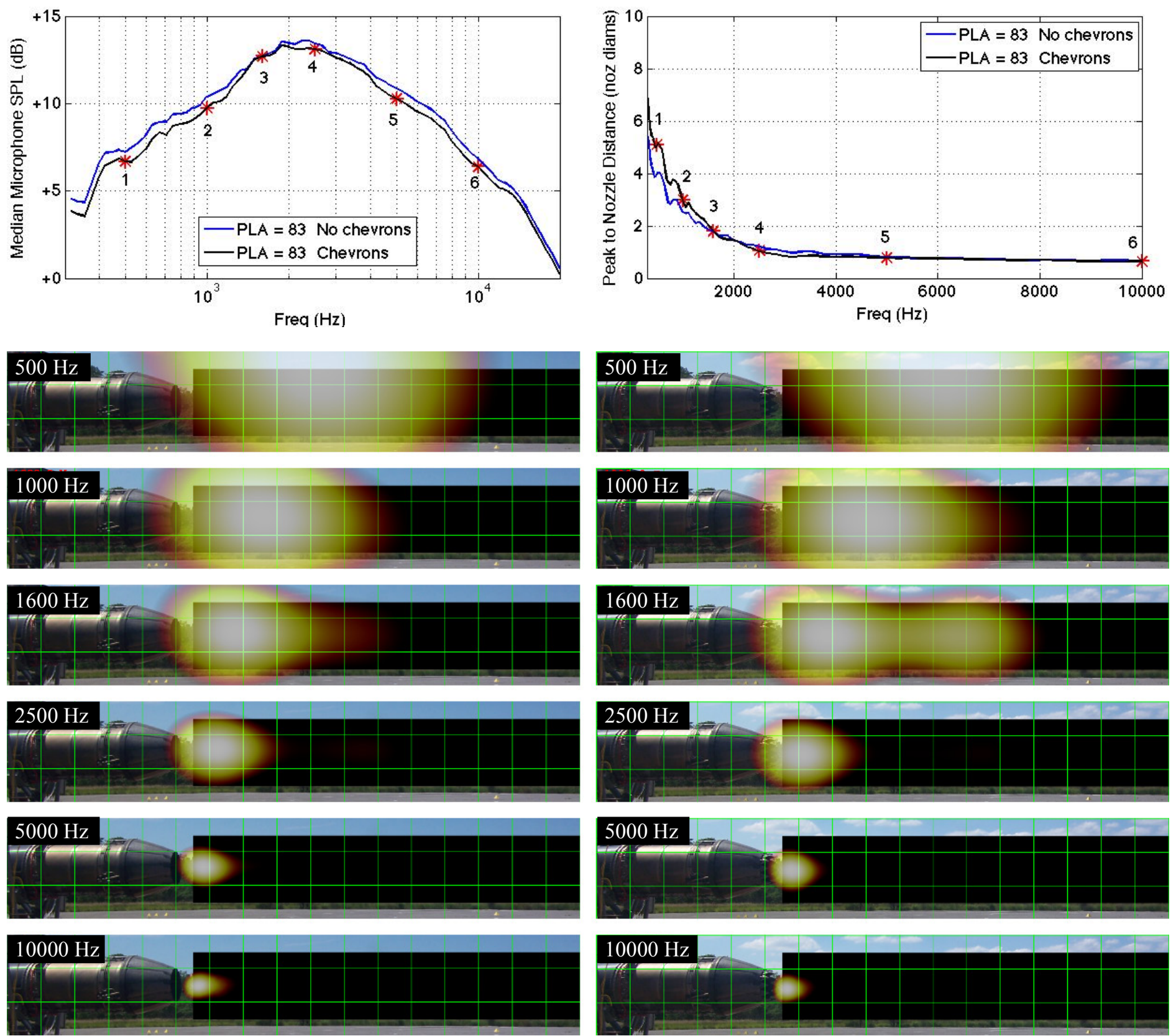

Figure 12.-No chevron (left) versus chevron (right) comparison for the full-scale engine operating with PLA $=83^{\circ}$. 

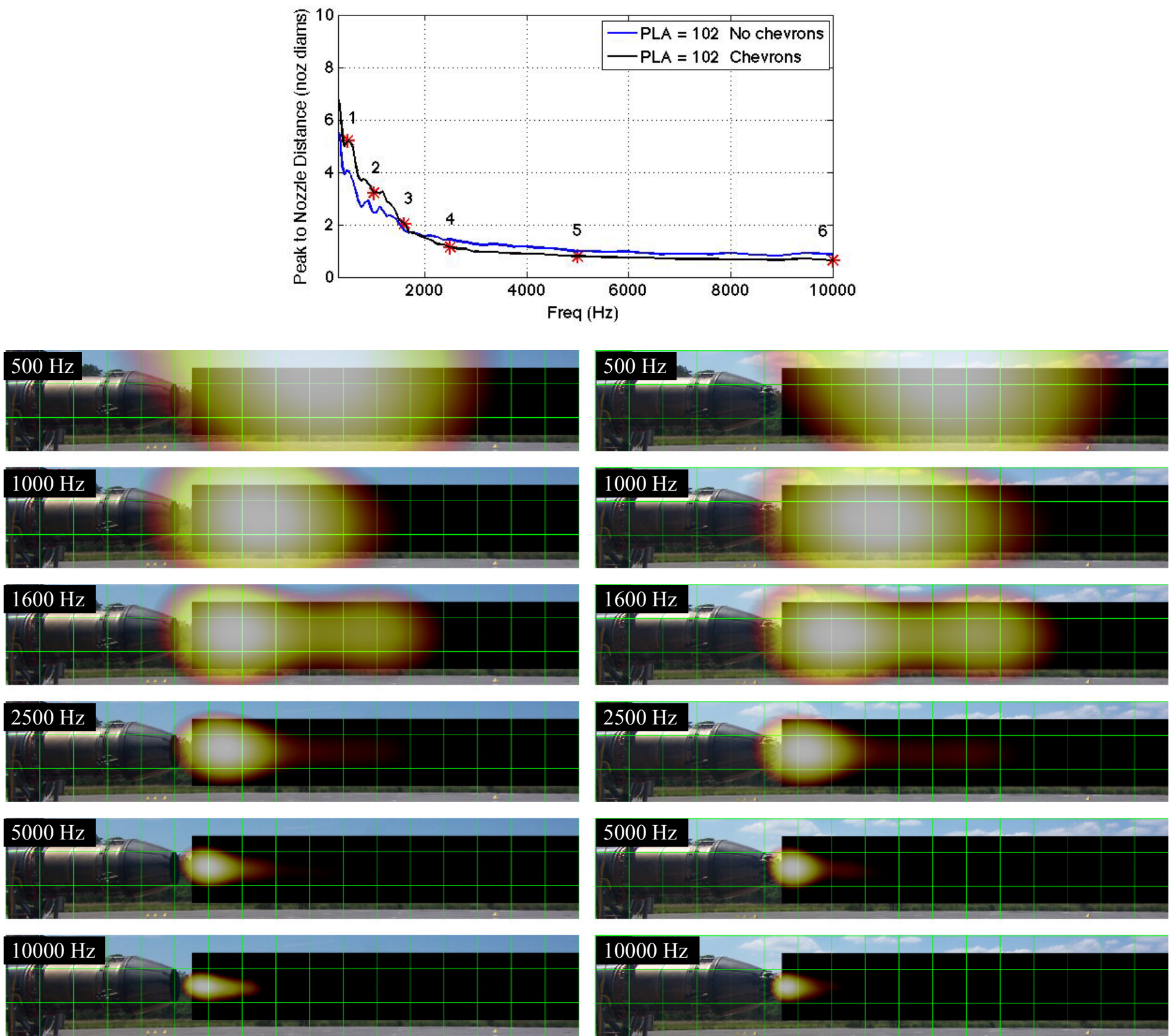

Figure 13.-No chevron (left) versus chevron (right) comparison for the full-scale engine operating at PLA $=102^{\circ}$. 

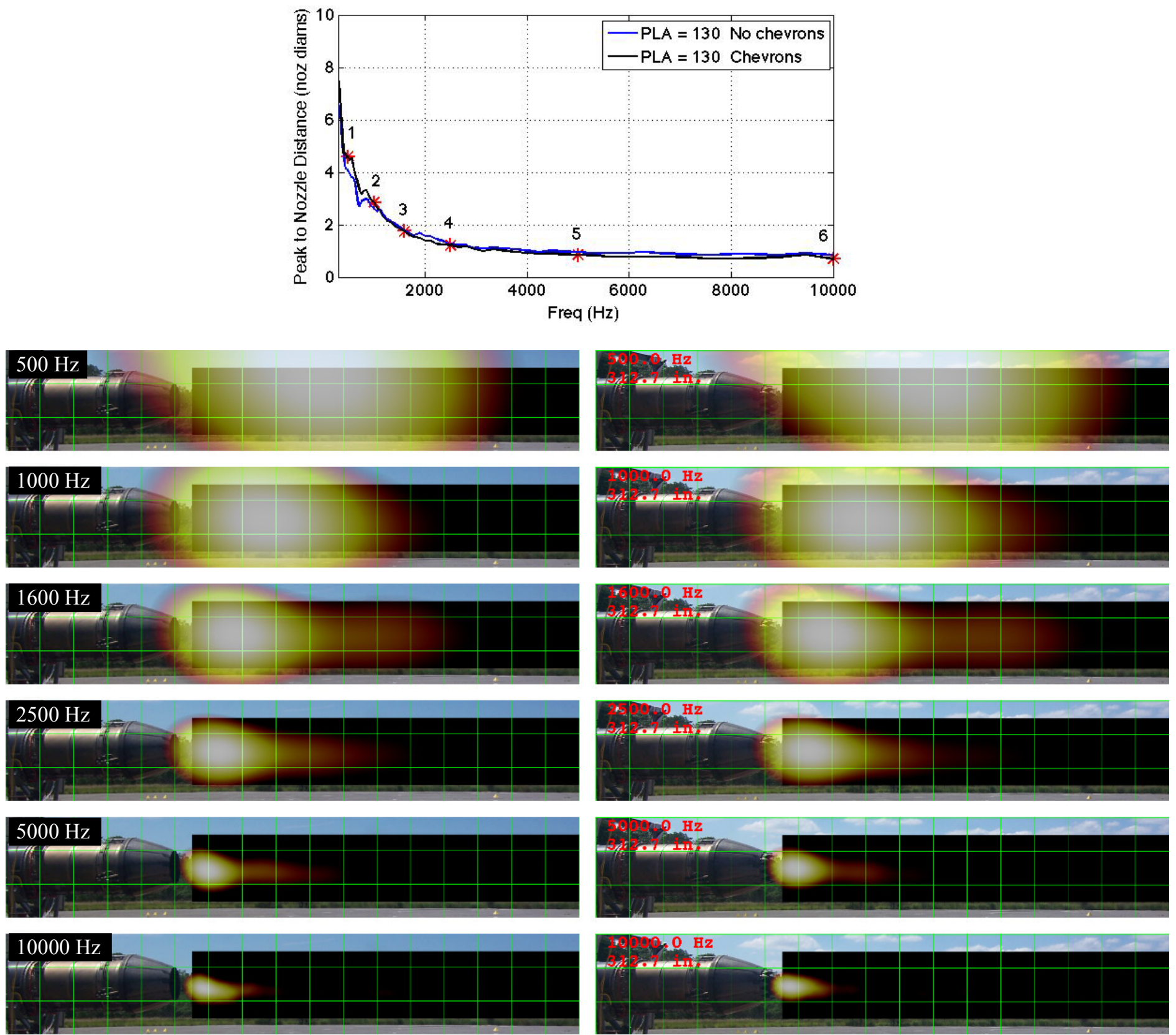

Figure 14.-No chevron (left) versus chevron (right) comparison for the full-scale engine operating with PLA $=130^{\circ}$. 

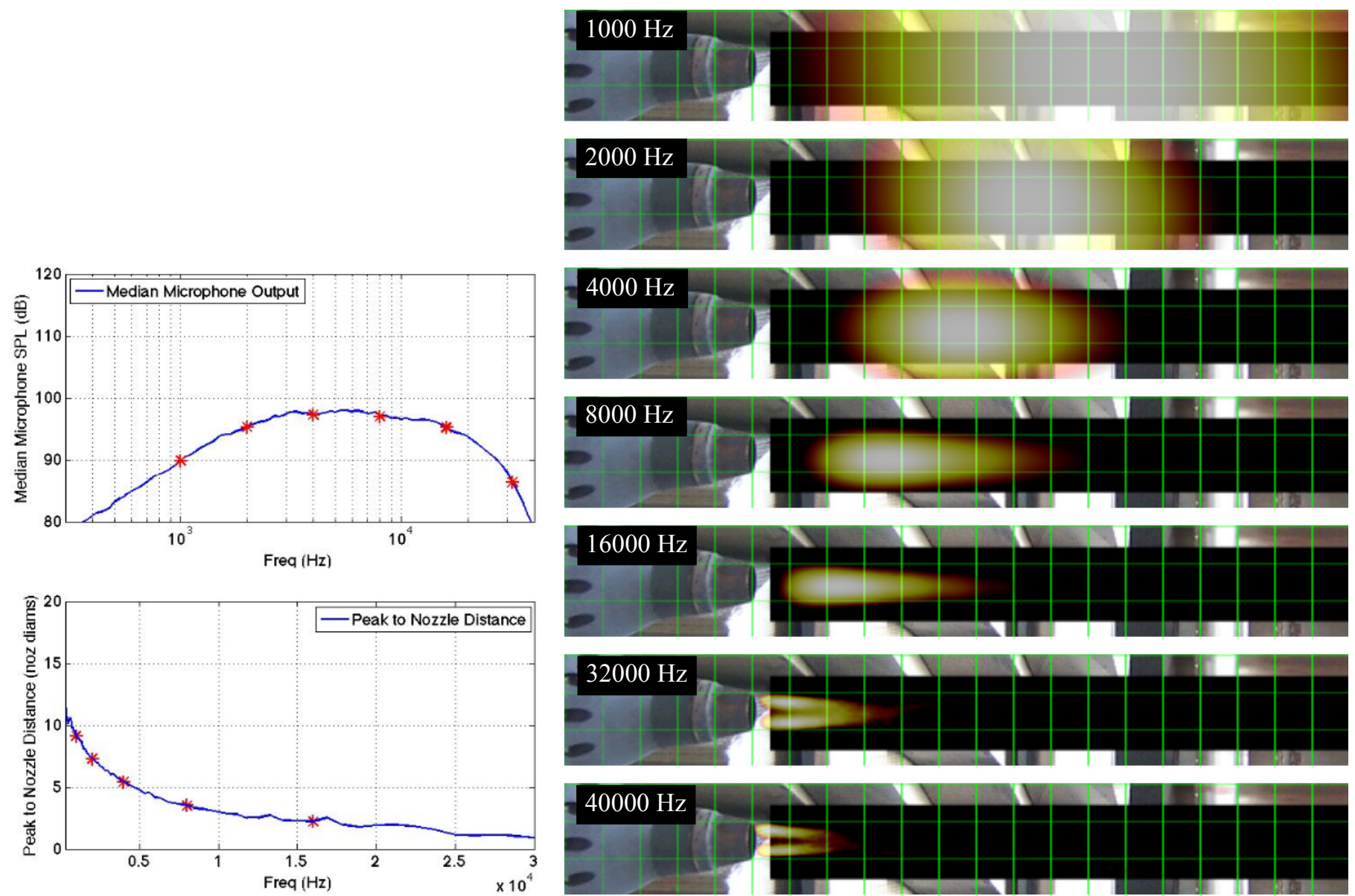

Figure 15.-Median mic spectra (upper left), peak location plot (lower left), and beamform maps for a $50.8 \mathrm{~mm}$ diameter round convergent nozzle operating at $\mathrm{M}_{\mathrm{jet}}=0.9, \mathrm{M}_{\mathrm{a}}=1.47, \mathrm{~T}_{\mathrm{s}} / \mathrm{T}_{\mathrm{amb}}=2.7$. 

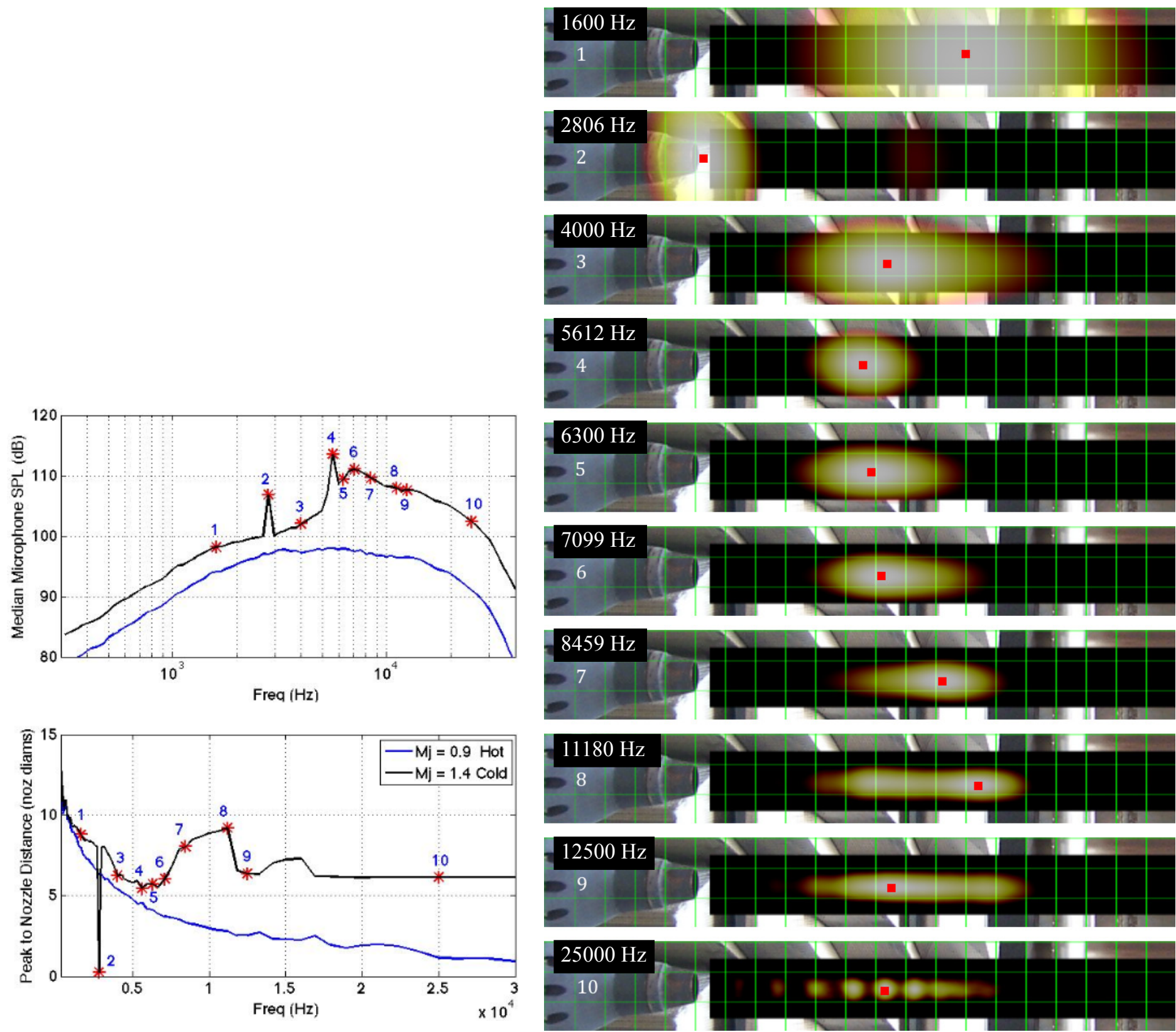

Figure 16.-Median mic spectra (upper left), peak location plot (lower left), and beamform maps for a $50.8 \mathrm{~mm}$ diameter round convergent nozzle operating at $\mathrm{M}_{\mathrm{jet}}=1.4, \mathrm{~T}_{\mathrm{s}} / \mathrm{T}_{\mathrm{amb}}=1.0$. 

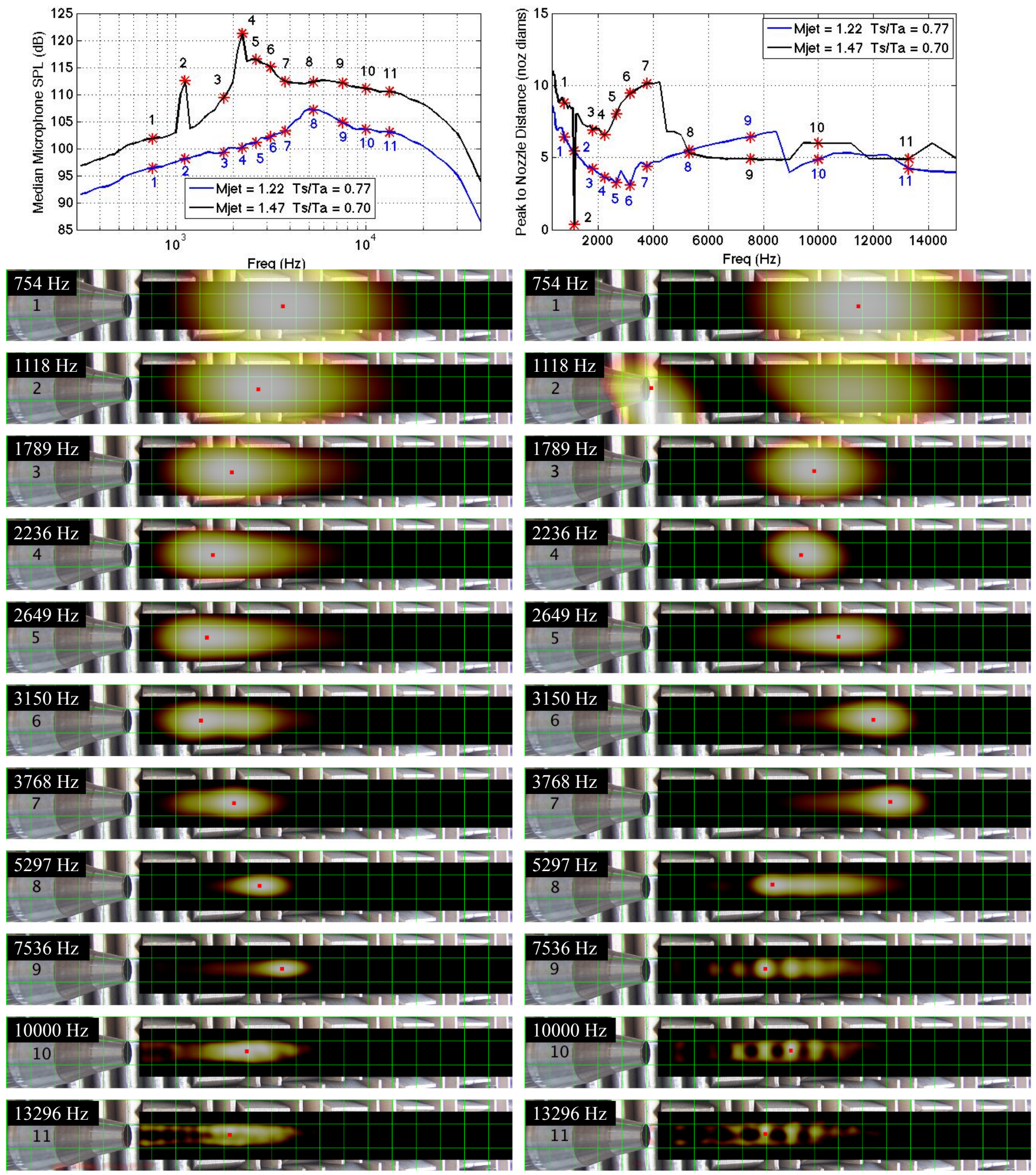

Figure 17.-Median mic spectra (upper left), peak location plot (upper right), and beamform maps (left Mjet $=1.22 \mathrm{Ts} / \mathrm{Ta}=0.77$, right Mjet $=1.47 \mathrm{Ts} / \mathrm{Ta}=0.70$ ) for the $1 / 4^{\text {th }}$ scale model of the F400 nozzle. 

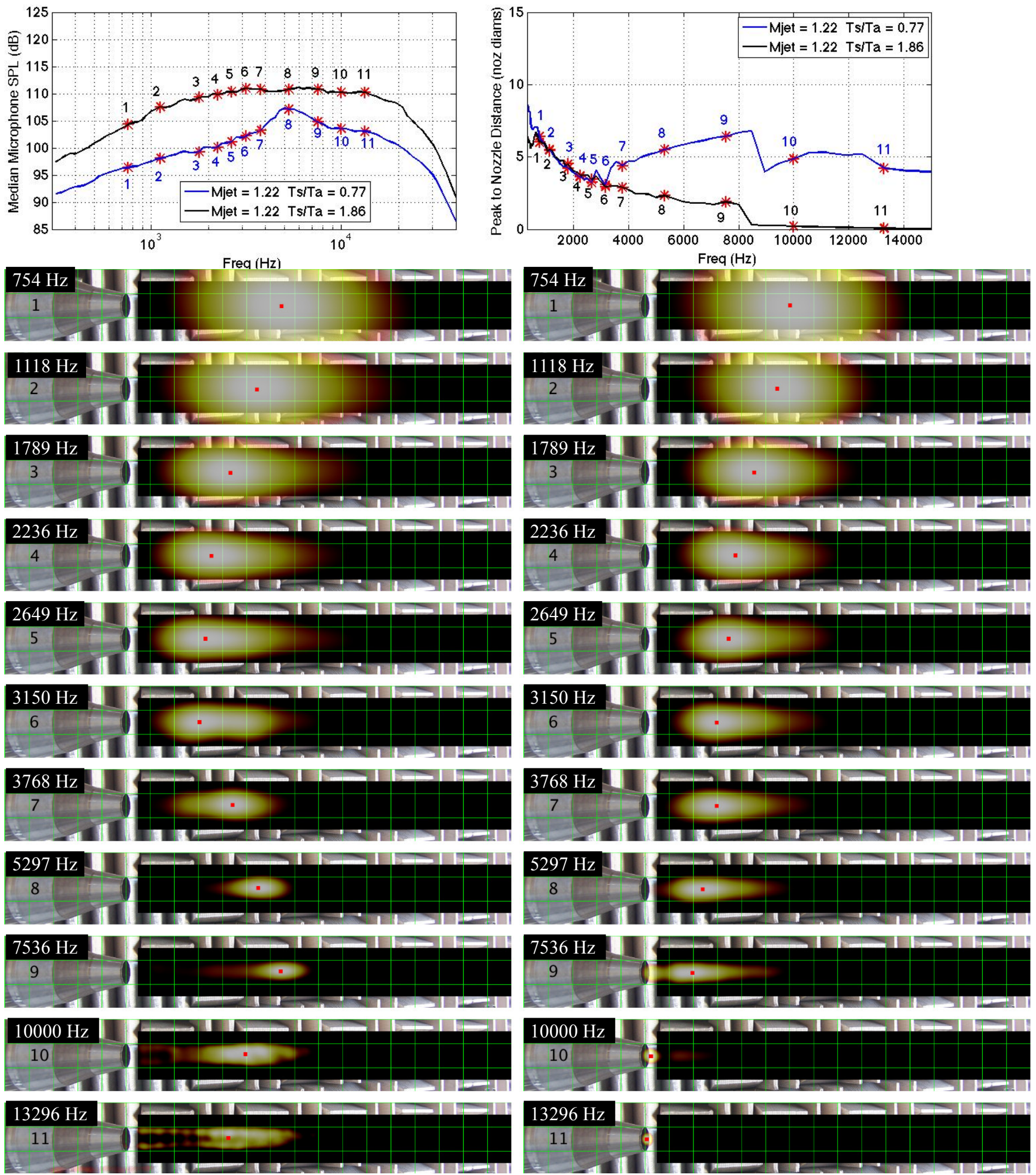

Figure 18. - Median mic spectra (upper left), peak location plot (upper right), and beamform maps (left Mjet $=1.22 \mathrm{Ts} / \mathrm{Ta}=0.77$, right Mjet $=1.22 \mathrm{Ts} / \mathrm{Ta}=1.86$ ) for the $1 / 4^{\text {th }}$ scale model of the F400 nozzle. 

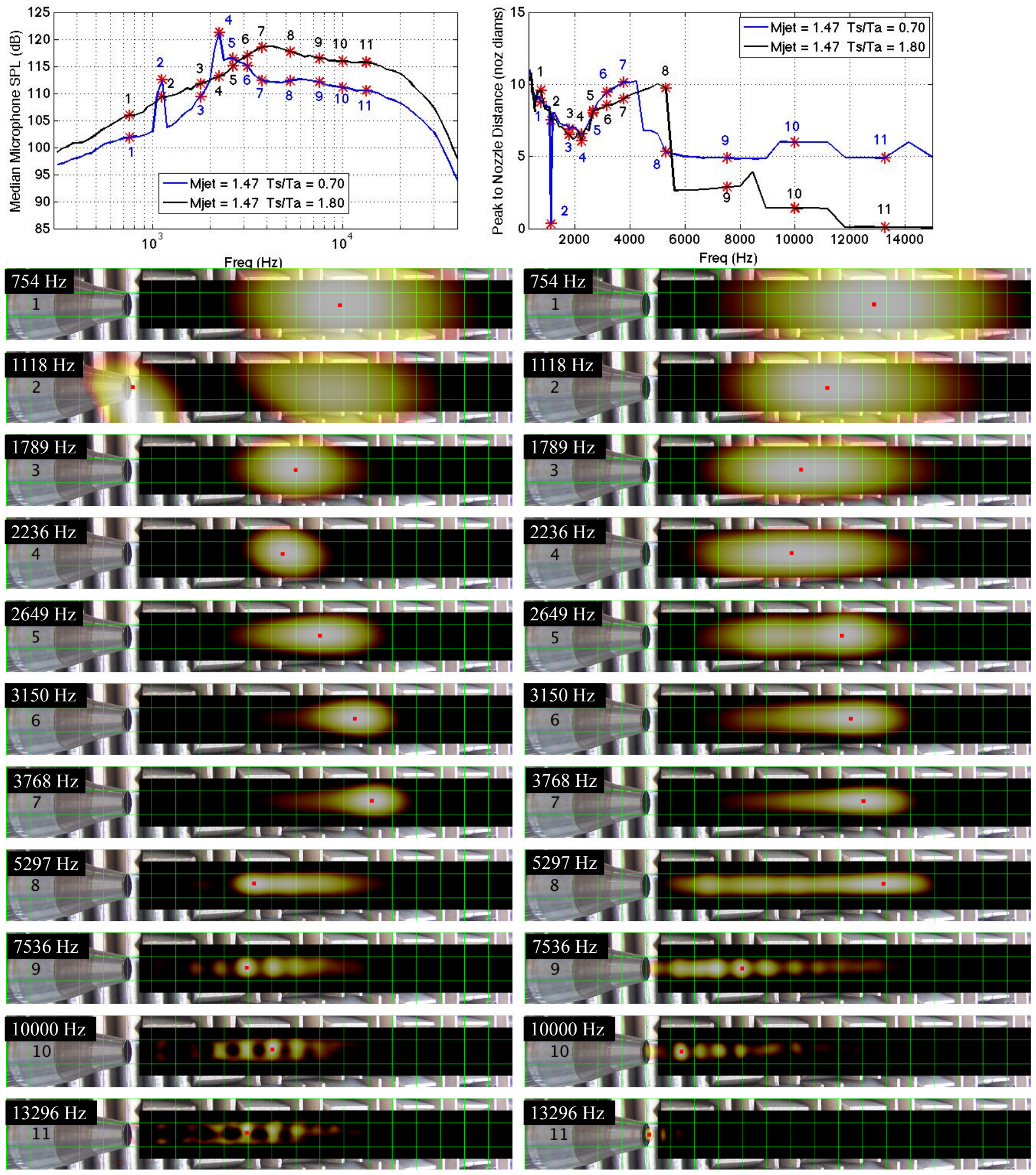

Figure 19.-Median mic spectra (upper left), peak location plot (upper right), and beamform maps (left Mjet $=1.47 \mathrm{Ts} / \mathrm{Ta}=0.70$, right Mjet $=1.47 \mathrm{Ts} / \mathrm{Ta}=1.80$ ) for the $1 / 4^{\text {th }}$ scale CD nozzle. 

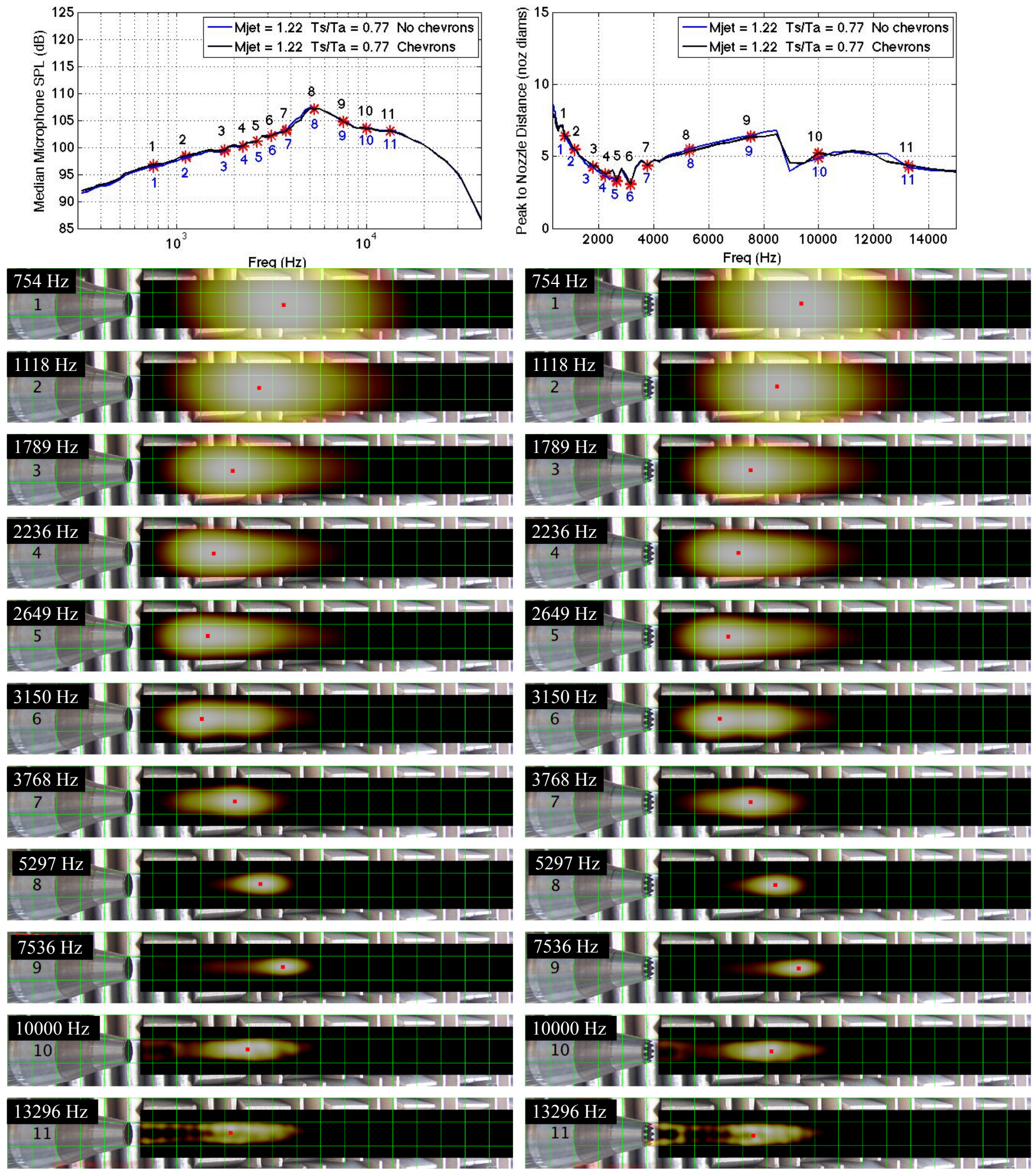

Figure 20.-No chevron (left) versus chevron (right) comparison of cold jets $\left(T_{s} / T_{a}=0.77\right)$ at $M_{j e t}=1.22$ for the $1 / 4^{\text {th }}$ scale $C D$ nozzle. 



Figure 21. - No chevron (left) versus chevron (right) comparison of cold jets $\left(\mathrm{T}_{\mathrm{s}} / \mathrm{T}_{\mathrm{a}}=0.77\right.$ ) at $\mathrm{M}_{\mathrm{jet}}=1.47$ for the $1 / 4^{\text {th }}$ scale $C D$ nozzle. 

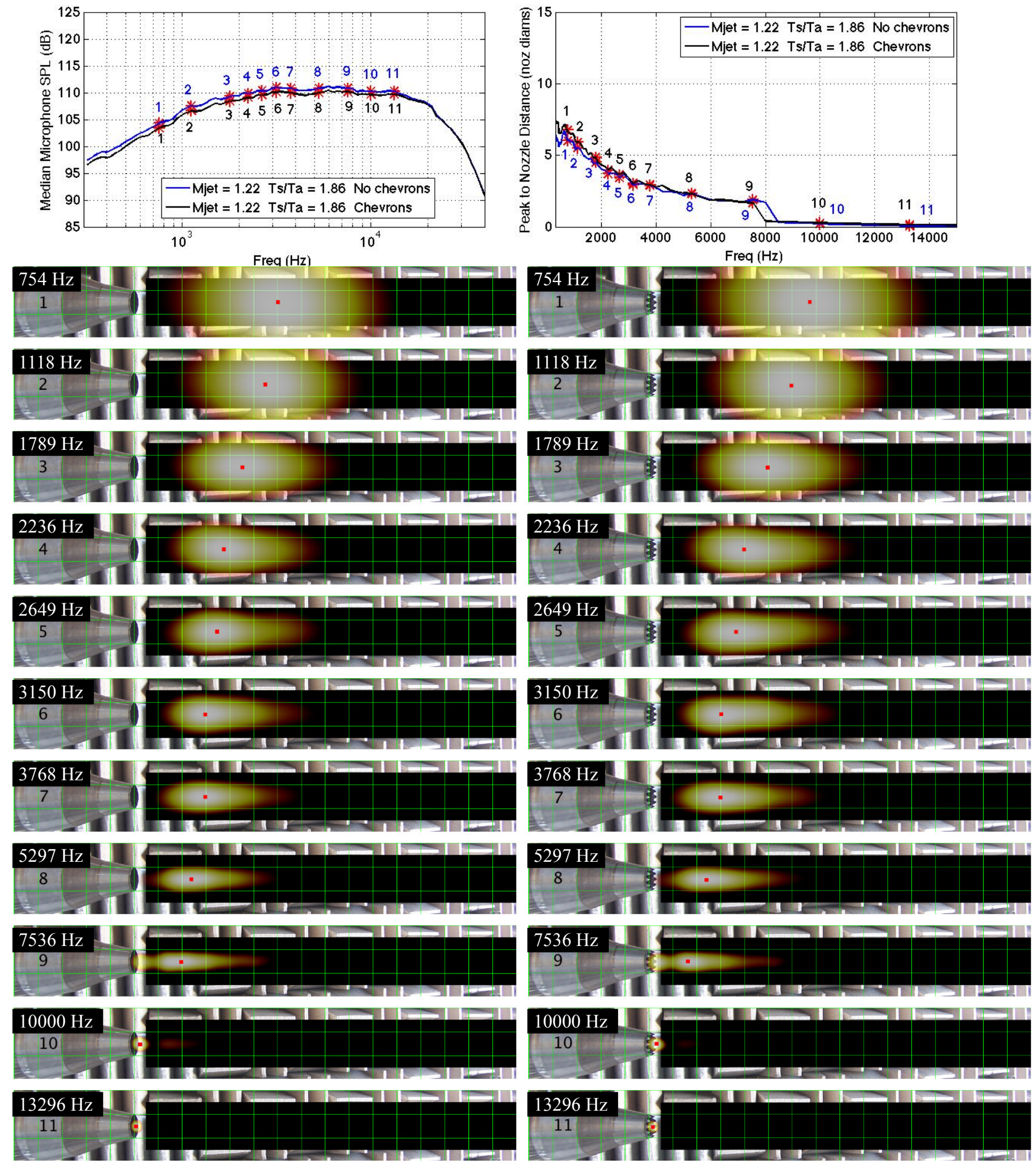

Figure 22.-No chevron (left) versus chevron (right) comparison of hot jets $\left(T_{s} / T_{a}=1.86\right)$ at $M_{\text {jet }}=1.22$ for the $1 / 4^{\text {th }}$ scale $C D$ nozzle. 

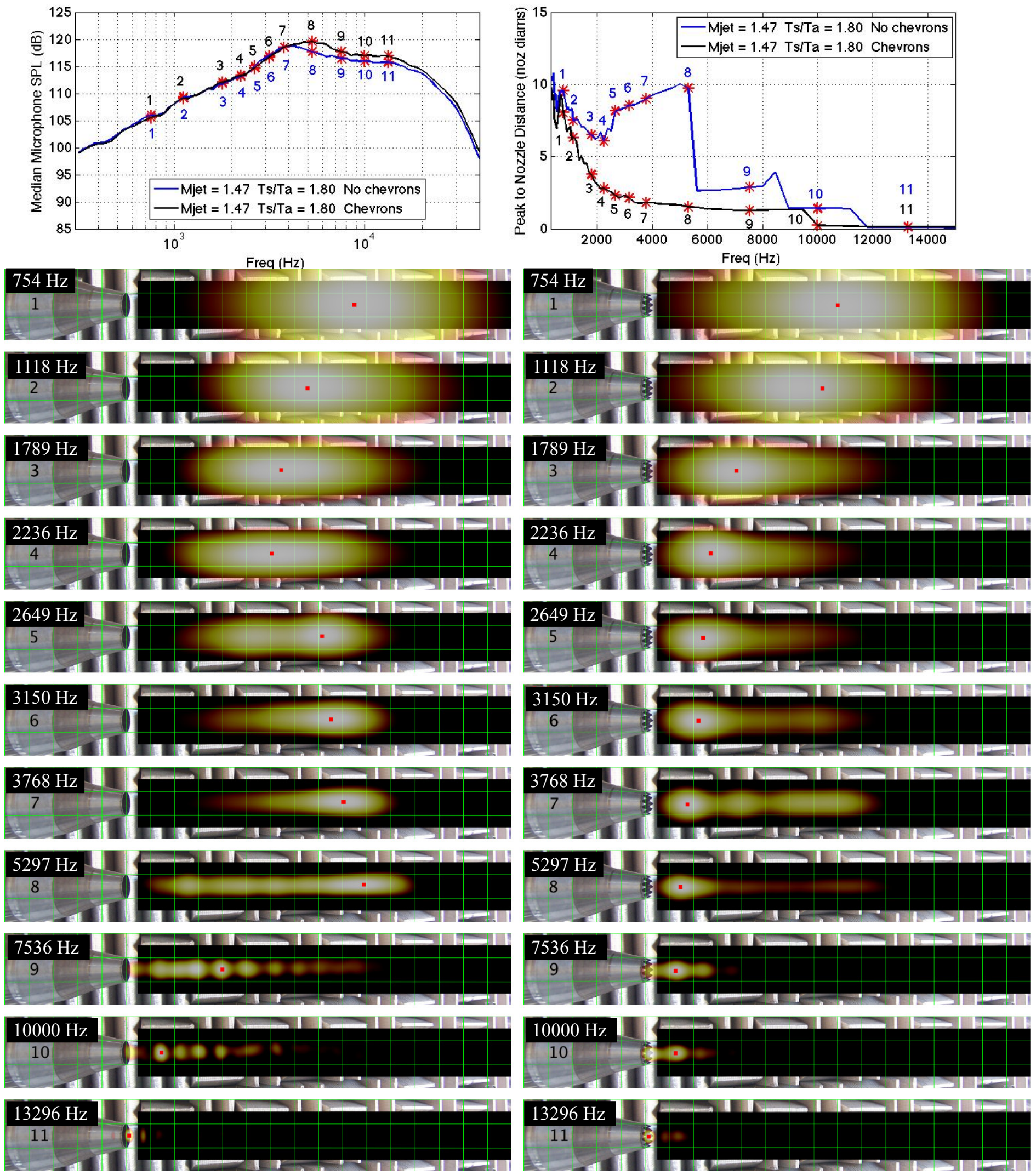

Figure 23.-No chevron (left) versus chevron (right) comparison of hot jets $\left(T_{s} / T_{a}=1.86\right)$ at $M_{\text {jet }}=1.47$ for the $1 / 4^{\text {th }}$ scale $C D$ nozzle. 


\begin{tabular}{|c|c|c|c|c|c|}
\hline \multicolumn{5}{|c|}{ REPORT DOCUMENTATION PAGE } & $\begin{array}{c}\text { Form Approved } \\
\text { OMB No. 0704-0188 }\end{array}$ \\
\hline \multicolumn{6}{|c|}{$\begin{array}{l}\text { The public reporting burden for this collection of information is estimated to average } 1 \text { hour per response, including the time for reviewing instructions, searching existing data sources, gathering and maintaining the } \\
\text { data needed, and completeting and reviewing the collection of information. Send comments regarding this burden estimate or any other aspect of this collection of information, including suggestions for reducing this } \\
\text { burden, to Department of Defense, Washington Headquarters Services, Directorate for Information Operations and Reports (0704-0188), } 1215 \text { Jefferson Davis Highway, Suite } 1204 \text {, Arlington, VA } 22202-4302 \text {. } \\
\text { Respondents should be aware that notwithstanding any other provision of law, no person shall be subject to any penalty for failing to comply with a collection of information if it does not display a currently valid OMB } \\
\text { control number. } \\
\text { PLEASE DO NOT RETURN YOUR FORM TO THE ABOVE ADDRESS. }\end{array}$} \\
\hline \multicolumn{2}{|c|}{$\begin{array}{l}\text { 1. REPORT DATE (DD-MM-YYYY) } \\
01-08-2010\end{array}$} & \multicolumn{3}{|c|}{$\begin{array}{l}\text { 2. REPORT TYPE } \\
\text { Technical Memorandum }\end{array}$} & 3. DATES COVERED (From - To) \\
\hline \multirow{3}{*}{\multicolumn{5}{|c|}{$\begin{array}{l}\text { 4. TITLE AND SUBTITLE } \\
\text { Phased Array Noise Source Localization Measurements of an F404 Nozzle Plume at Both } \\
\text { Full and Model Scale }\end{array}$}} & 5a. CONTRACT NUMBER \\
\hline & & & & & 5b. GRANT NUMBER \\
\hline & & & & & 5c. PROGRAM ELEMENT NUMBER \\
\hline \multirow{3}{*}{\multicolumn{5}{|c|}{$\begin{array}{l}\text { 6. AUTHOR(S) } \\
\text { Podboy, Gary, G.; Bridges, James, E.; Henderson, Brenda, S. }\end{array}$}} & 5d. PROJECT NUMBER \\
\hline & & & & & 5e. TASK NUMBER \\
\hline & & & & & $\begin{array}{l}\text { 5f. WORK UNIT NUMBER } \\
\text { WBS 561581.02.08.03.18.02 }\end{array}$ \\
\hline \multicolumn{5}{|c|}{$\begin{array}{l}\text { 7. PERFORMING ORGANIZATION NAME(S) AND ADDRESS(ES) } \\
\text { National Aeronautics and Space Administration } \\
\text { John H. Glenn Research Center at Lewis Field } \\
\text { Cleveland, Ohio 44135-3191 }\end{array}$} & $\begin{array}{l}\text { 8. PERFORMING ORGANIZATION } \\
\text { REPORT NUMBER } \\
\text { E-17302 }\end{array}$ \\
\hline \multirow{2}{*}{\multicolumn{5}{|c|}{$\begin{array}{l}\text { 9. SPONSORING/MONITORING AGENCY NAME(S) AND ADDRESS(ES) } \\
\text { National Aeronautics and Space Administration } \\
\text { Washington, DC 20546-0001 }\end{array}$}} & $\begin{array}{l}\text { 10. SPONSORING/MONITOR'S } \\
\text { ACRONYM(S) } \\
\text { NASA }\end{array}$ \\
\hline & & & & & $\begin{array}{l}\text { 11. SPONSORING/MONITORING } \\
\text { REPORT NUMBER } \\
\text { NASA/TM-2010-216366 }\end{array}$ \\
\hline \multicolumn{6}{|c|}{$\begin{array}{l}\text { 12. DISTRIBUTION/AVAILABILITY STATEMENT } \\
\text { Unclassified-Unlimited } \\
\text { Subject Category: } 71 \\
\text { Available electronically at http://gltrs.grc.nasa.gov } \\
\text { This publication is available from the NASA Center for AeroSpace Information, 443-757-5802 }\end{array}$} \\
\hline \multicolumn{6}{|c|}{ 13. SUPPLEMENTARY NOTES } \\
\hline \multicolumn{6}{|c|}{$\begin{array}{l}\text { 14. ABSTRACT } \\
\text { A } 48 \text {-microphone planar phased array system was used to acquire jet noise source localization data on both a full-scale F404-GE-F400 } \\
\text { engine and on a 1/4th scale model of a F400 series nozzle. The full-scale engine test data show the location of the dominant noise sources in } \\
\text { the jet plume as a function of frequency for the engine in both baseline (no chevron) and chevron configurations. Data are presented for the } \\
\text { engine operating both with and without afterburners. Based on lessons learned during this test, a set of recommendations are provided } \\
\text { regarding how the phased array measurement system could be modified in order to obtain more useful acoustic source localization data on } \\
\text { high-performance military engines in the future. The data obtained on the } 1 / 4 \text { th scale F400 series nozzle provide useful insights regarding } \\
\text { the full-scale engine jet noise source mechanisms, and document some of the differences associated with testing at model-scale versus full- } \\
\text { scale. }\end{array}$} \\
\hline \multicolumn{6}{|c|}{$\begin{array}{l}\text { 15. SUBJECT TERMS } \\
\text { Array; Noise source; F404 }\end{array}$} \\
\hline \multicolumn{3}{|c|}{ 16. SECURITY CLASSIFICATION OF: } & $\begin{array}{l}\text { 17. LIMITATION OF } \\
\text { ABSTRACT }\end{array}$ & $\begin{array}{l}\text { 18. NUMBER } \\
\text { OF }\end{array}$ & $\begin{array}{l}\text { 19a. NAME OF RESPONSIBLE PERSON } \\
\text { STI Help Desk (email:help } @ \text { sti.nasa.gov) }\end{array}$ \\
\hline $\begin{array}{l}\text { a. REPORT } \\
\text { U }\end{array}$ & $\begin{array}{l}\text { b. ABSTRACT } \\
\mathrm{U}\end{array}$ & $\begin{array}{l}\text { c. THIS } \\
\text { PAGE } \\
\text { U }\end{array}$ & UU & $\begin{array}{l}\text { PAGES } \\
35\end{array}$ & $\begin{array}{l}\text { 19b. TELEPHONE NUMBER (include area code) } \\
443-757-5802\end{array}$ \\
\hline
\end{tabular}



